\title{
Estimation of the susceptibility of a road network to shallow landslides with the integration of the sediment connectivity
}

\author{
Massimiliano Bordoni ${ }^{1}$, M. Giuseppina Persichillo ${ }^{1}$, Claudia Meisina ${ }^{1},{\text { Stefano } \text { Crema }^{2} \text {, Marco Cavalli }}^{2}$, \\ Carlotta Bartelletti $^{3}$, Yuri Galanti ${ }^{3}$, Michele Barsanti ${ }^{4}$, Roberto Giannecchini ${ }^{3}$, and Giacomo D'Amato Avanzi ${ }^{3}$ \\ ${ }^{1}$ Department of Earth and Environmental Sciences, University of Pavia, Pavia, 27100, Italy \\ ${ }^{2}$ Research Institute for Geo-Hydrological Protection, National Research Council, Padova, 35127, Italy \\ ${ }^{3}$ Department of Earth Sciences, University of Pisa, Pisa, 56126, Italy \\ ${ }^{4}$ Department of Civil and Industrial Engineering, University of Pisa, Pisa, 56126, Italy
}

Correspondence: Massimiliano Bordoni (massimiliano.bordoni01@universitadipavia.it)

Received: 28 December 2017 - Discussion started: 24 January 2018

Revised: 8 May 2018 - Accepted: 8 June 2018 - Published: 22 June 2018

\begin{abstract}
Landslides cause severe damage to the road network of the hit zone, in terms of both direct (partial or complete destruction of a road or blockages) and indirect (traffic restriction or the cut-off of a certain area) costs. Thus, the identification of the parts of the road network that are more susceptible to landslides is fundamental to reduce the risk to the population potentially exposed and the financial expense caused by the damage. For these reasons, this paper aimed to develop and test a data-driven model for the identification of road sectors that are susceptible to being hit by shallow landslides triggered in slopes upstream from the infrastructure. This model was based on the Generalized Additive Method, where the function relating predictors and response variable is an empirically fitted smooth function that allows fitting the data in the more likely functional form, considering also non-linear relations. This work also analyzed the importance, on the estimation of the susceptibility, of considering or not the sediment connectivity, which influences the path and the travel distance of the materials mobilized by a slope failure until hitting a potential barrier such as a road. The study was carried out in a catchment of northeastern Oltrepò Pavese (northern Italy), where several shallow landslides affected roads in the last 8 years. The most significant explanatory variables were selected by a random partition of the available dataset in two parts (training and test subsets), 100 times according to a bootstrap procedure. These variables (selected 80 times by the bootstrap procedure) were used to build the final susceptibility model, the accuracy of which was estimated through a 100 -fold repetition
\end{abstract}

of the holdout method for regression, based on the training and test sets created through the 100 bootstrap model selection. The presented methodology allows the identification, in a robust and reliable way, of the most susceptible road sectors that could be hit by sediments delivered by landslides. The best predictive capability was obtained using a model in which the index of connectivity was also calculated according to a linear relationship, was considered. Most susceptible road traits resulted to be located below steep slopes with a limited height (lower than $50 \mathrm{~m}$ ), where sediment connectivity is high. Different land use scenarios were considered in order to estimate possible changes in road susceptibility. Land use classes of the study area were characterized by similar connectivity features. As a consequence, variations on the susceptibility of the road network according to different scenarios of distribution of land cover were limited. The results of this research demonstrate the ability of the developed methodology in the assessment of susceptible roads. This could give the managers of infrastructure information about the criticality of the different road traits, thereby allowing attention and economic budgets to be shifted towards the most critical assets, where structural and non-structural mitigation measures could be implemented. 


\section{Introduction}

Landslides are important geohazards in many regions of the world. They cause severe economic damage each year in the order of hundreds of billions of dollars (Zezere et al., 2007; Salvati et al., 2014; Gariano and Guzzetti, 2016). Slope instability induces significant damages, deaths and economic losses to infrastructures, to roads in particular (Van Westen et al., 2006; Klose et al., 2015). The main negative consequences of instability phenomena on roads are (Bil et al., 2014) (i) their partial or complete destruction, which can also cause human losses; (ii) the traffic restriction due to the blockage of a hit road, which may affect the entire network causing congestion and (iii) the cut-off of certain areas that cannot be reached by alternative routes.

Thus, it is fundamental to identify what sectors of a road network are more susceptible to landslides, in order to reduce the risk to the population potentially exposed and the monetary expense caused by road damage. This aim is particularly important, also because much research (Nemry and Demirel, 2012; Michaelides, 2014; Strauch et al., 2015; Klose et al., 2017; Matulla et al., 2017) has stressed that the exposure of road networks to slope instabilities could increase as a consequence of the climate change and of the economic rising income in different countries.

According to the geomorphological and triggering features, landslides affecting roads can be distinguished as (i) landslides in correspondence of the infrastructure and (ii) landslides triggered in a natural or an engineered hillslope upstream to the road, whose transportation and/or accumulation zone hit the infrastructure.

The triggering mechanisms of the first landslide type are strictly related to local hydrological and geotechnical settings that are related to the road presence. These factors generally highlight incorrect construction or management of the infrastructure, regardless of the natural features of the slopes where the road was built (Sidle and Ochiai, 2006; Muenchow et al., 2012; D'Amato Avanzi et al., 2013; Brenning et al., 2015). In contrast, the triggering mechanism and landslide runout of the second landslide type can be related to the geological, geomorphological and hydrological predisposing factors of the natural or engineered slopes upstream to the roads. Furthermore, these events are the most widespread in terms of affected routes, in many cases including the involvement of extended sectors of hilly and mountainous road networks (Quinn et al., 2010; Bil et al., 2014).

In recent years, several data-driven methodologies were built to identify the susceptible sectors of a road network to landslides (Budetta, 2004; Hearn et al., 2008; Jaiswal et al., 2010a, b, 2011; Quinn et al., 2010; Michoud et al., 2012; Tarolli et al., 2013; Bil et al., 2014, 2017; Penna et al., 2014; Ramesh and Anbazhagan, 2015; Tarolli and Sofia, 2016; Winter et al., 2016; Donnini et al., 2017; Pellicani et al., 2017; Postance et al., 2017; Martinovic et al., 2018). These methods are based on quantitative statistical relationships be- tween predisposing factors and a response variable. They assume that an event is most likely to occur under similar ground conditions to previous events (Varnes, 1984). They present the advantage of being more objective and easily applicable on different scales (from site-specific to regional), as well as capable of managing large sets of predisposing factors (Corominas et al., 2014). Data-driven models depend strictly on the reliability of the inventories of the response variable (Guzzetti et al., 2006; Corominas et al., 2014). Aside from this limitation, data-driven methods are most flexible to be used at different scales of analysis (from site-specific to regional scale) and do not require a lot of data to compared to the physically based models (Corominas et al., 2014).

Data-driven models used for the characterization of susceptible routes were based on a multi-variate analysis (Dai and Lee, 2002; Chen and Wang, 2007), which predicts the spatial distribution of roads hit by landslides through the estimation of the relations and the relative weight between the predisposing factors and the response variable (roads affected by landslides). Such methods do not consider nonlinear relations between the predisposing factors and the response variable. However, the non-linearity of the system should be considered, since changing the environmental and geological conditions leads to a consequent interaction of the mobilized materials with roads (Goetz et al., 2011). Moreover, neglecting a possible non-linearity in the model could decrease its predictive performance, due to limitation in highlighting the complex behaviours of the phenomena (Phillips, 2003, 2006). Thus, it could be useful to implement a methodology that considers also a non-linear regression technique, such as the Generalized Additive Model (GAM; Hastie and Tibshirani, 1990).

Furthermore, previous methods did not take into account the potential slope sediments mobilized by the landslide that reach the road network in the downstream area. This aspect is well described by the amount in sediment connectivity, which influences the path and the travel distance of the materials mobilized by a slope failure until reaching a potential natural or anthropogenic barrier (e.g., river or road) (Cavalli et al., 2013; Tarolli and Sofia, 2016; Persichillo et al., 2018). In this way, the landslide runout can be estimated and inserted when modelling road susceptibility without employing numerical or physical methods, which require rheological and geotechnical data not easily measurable for the slope materials (Hungr, 1995; Fannin and Wise, 2001; Pastor et al., 2014; Fan et al., 2017).

Scenarios of road susceptibility distribution related to the modifications of land use in a particular area were not considered so far. However, land use changes can have significant impacts both on the locations of landslide triggering zones (Glade, 2003; Begueria, 2006; Reichenbach et al., 2014; Persichillo et al., 2017a) and on the connectivity of the mobilized sediments (Foerster et al., 2014; Lopez-Vicente et al., 2013 , 2016). Thus, susceptibility scenarios of different land use distributions may allow the identification of land man- 
agement practices able to reduce the slope instability which can induce damages to roads.

For these reasons, a non-linear data-driven method was developed and tested for the identification of road network sectors more susceptible to shallow landslides triggered in slopes upstream to an infrastructure. The main objectives of the paper are (i) the development and testing of a datadriven non-linear methodology, based on the GAM, that is able to identify the relations between predisposing and response variables for the assessment of road sectors susceptible to shallow landslides triggered upstream of the infrastructure; (ii) the importance of considering sediment connectivity in the susceptible road segments modelling and (iii) the analysis of the effects resulting from different scenarios of land use distribution on the road sectors potentially affected by shallow landslides.

\section{The study area}

The analysis was carried out in a catchment located between Scuropasso river and Versa river, in Oltrepò Pavese, in the northern termination part of the Italian Apennines (Fig. 1). The study area is $14 \mathrm{~km}^{2}$ wide and presents an elevation range between 88 and $295 \mathrm{~m}$ a.s.l. The morphological structure is typical of the Pede-Apennine margin of Oltrepò Pavese and is closely related to both the lithology and the tectonic or neotectonic setting of the Apennine margin. It is characterized by a medium-high slope gradient, with slope angles higher than $10^{\circ}$, with prominent altimetric irregularities along ridge lines and channel network in narrow valleys (Bordoni et al., 2015). Bedrock is characterized by a Mio-Pliocenic succession formed by medium low-permeable arenaceous conglomeratic materials (Monte Arzolo Sandstones, Rocca Ticozzi Conglomerates) overlying impermeable silty-sandy marly bedrock (Montù Beccaria Formation, Sant'Agata Fossili Marls) and evaporitic chalky marls and gypsum (Gessoso-Solfifera Formation) (Vercesi and Scagni, 1984). Superficial soils, derived by bedrock weathering, are mainly clayey-sandy silts and clayey-silty sands. Soil depth has values lower than $2.5 \mathrm{~m}$.

Land use maps of the study area have been available since 1954. The land use map of 1954 was realized through aerial photographs from Gruppo Aereo Italiano (Italian Aerial Group), with a resolution of $0.5 \mathrm{~m}$. Moreover, the land use map from 1980 was obtained from photo interpretation at a scale of 1:50000 from the TEM1 flight (scale 1:20000). Land use maps from 2000, 2007, 2012 and 2015 were provided by the Lombardy Region and shared as part of the Infrastructure for Spatial Information in Lombardy (IIT) via the Geoportal (Lombardy Region Geoportal: http:/www.cartografia.regione.lombardia.it/ geoportale, last access: 11 December 2017). The map of 2000 was obtained from the photo interpretation of aerial images of Flight IT2000, with a resolution of $1 \mathrm{~m}$, while the land use map of 2007 was realized by using colour and infrared orthophotos from Flight IT2007, with a resolution of $0.5 \mathrm{~m}$. The maps of 2012 and 2015, which corresponded to the actual situation, were realized through the photointerpretation of aerial photos realized by Agency for Disbursement in Agriculture (AGEA). The photo-interpretation was also supported by auxiliary data of Lombardy Region databases (e.g., Regional Agricultural Information System, Forest Types maps, map of the resident population, Archive of Integrated Activities production). The overall accuracies of maps obtained for Lombardy Region using this methodology was reported in Zaffaroni (2010) as approximately $95 \%$. More detailed information about the method to create these maps is available in Fasolini (2014).

The study area is characterized by traditional viticulture vocation with grapevine cultivation representing the main economic branch. Till the 1980 s, more than $90 \%$ of the territory was covered by cultivated vineyards, where manual cultivation practices predominated (Fig. 2a, b, c). This situation represented the highest diffusion of vineyards in the study area, identifying all the hillslopes that are effectively adapted for grapevine plantation and cultivation. Instead, in the last 40 years, more than $40 \%$ of previously cultivated slopes were abandoned, with a corresponding progressive increase in woodlands (+13\% from 1980 to 2007-2015) and in uncultivated areas generally composed of shrubs and grasses (+10\% from 1980 to 2007-2015, Fig. 2a, d). Between 2007 and 2015, land use classes distribution remained steady. In the 2007-2015 time span, $49 \%$ of the area was occupied by vineyards, $10 \%$ by uncultivated areas, $16 \%$ by woodlands and $16 \%$ by urban areas (Fig. 2d). Other land use classes are present in a percentage lower than $5 \%$.

This abandonment was due to the conversion from manual to mechanical cultivation practices that increased the difficulties in the maintenance of vineyards, especially for those located on very steep slopes $\left(>25^{\circ}\right.$ ) (Persichillo et al., 2017a). Moreover, societal changes, together with the decreasing number of people actively cultivating the area, caused a reduction in land care practices and maintenance works in both abandoned and cultivated vineyards (Persichillo et al., 2017a, 2018).

A primary road network (81 km long and generally $3-5 \mathrm{~m}$ wide) crosses the study area and is composed of provincial and municipal roads that connect different villages and towns (Fig. 3). The roads were built in correspondence of the valley floors or in the medium part of a hillslope, cutting its continuity. In the second case, a 3-5 m height trench was built upstream to the road sector.

This area was recently affected by several shallow landslides triggered by intense rainfall events (Bordoni et al., 2015). The most important one occurred in 27-28 April 2009 $(160 \mathrm{~mm} / 62 \mathrm{~h})$, and induced 532 failures; other shallow landslides occurred during the events of March and April 2013 and of 28 February-2 March 2014, triggering 19 and 18 shallow failures, respectively. Lower numbers of phenom- 


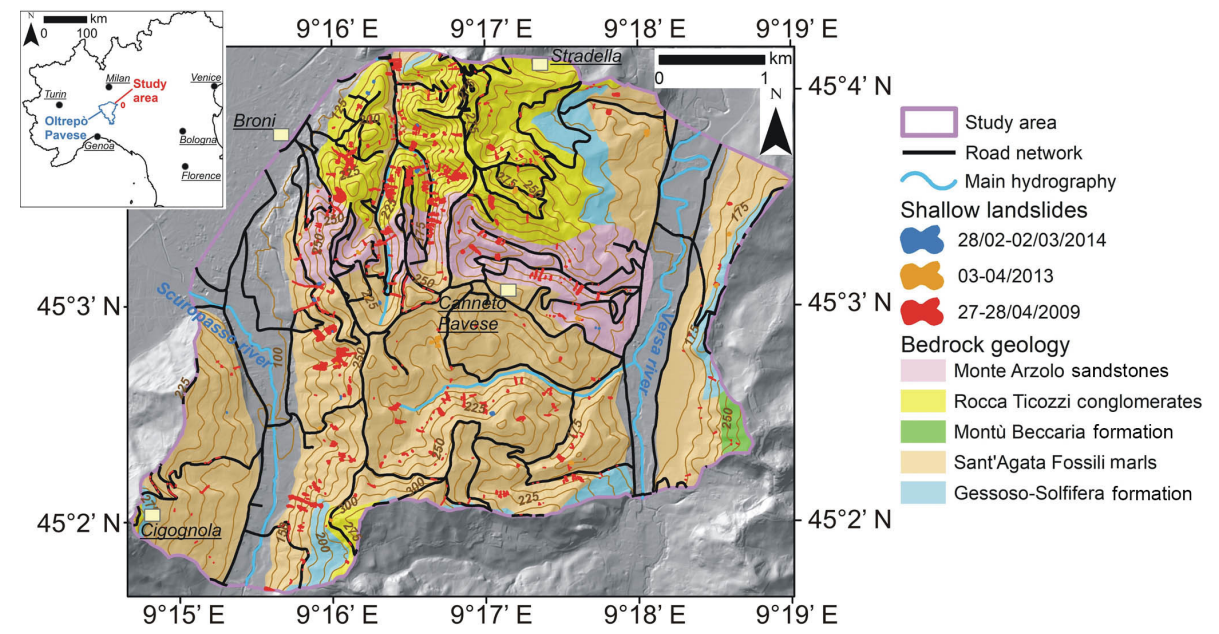

Figure 1. Geological setting and shallow landslide distribution of the study area.

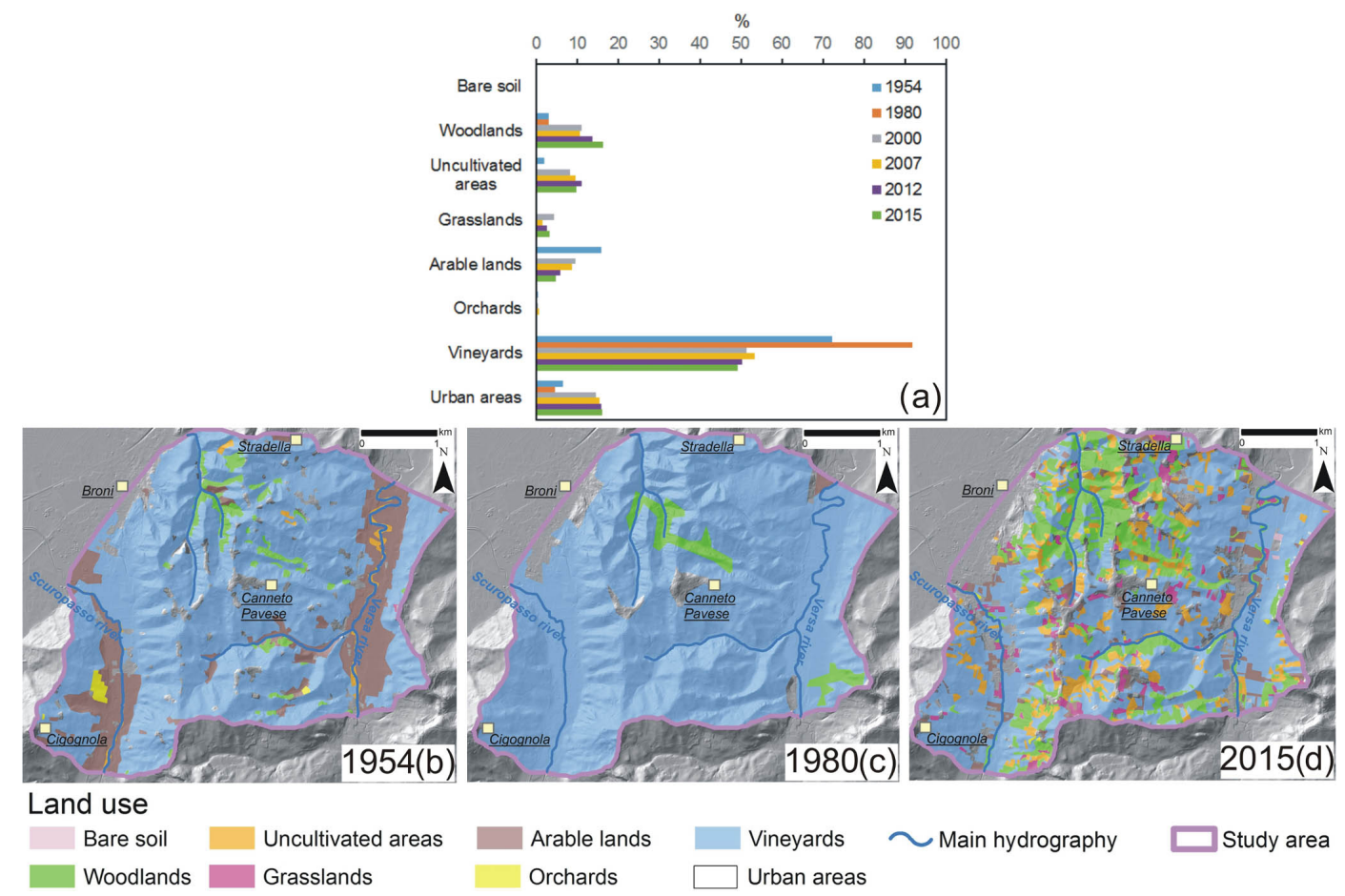

Figure 2. Land use distribution and land use changes in the period 1954-2015: (a) percentage of the area occupied by each land use class during the analyzed period; (b) land use distribution in 1954; (c) land use distribution in 1980 and (d) land use distribution in 2015. Land use maps were provided by the Lombardy Region and shared as part of the Infrastructure for Spatial Information in Lombardy (IIT) via the Geoportal (Lombardy Region Geoportal: http://www.cartografia.regione.lombardia.it/geoportale, last access: 11 December 2017). The detailed information regarding the method to create these maps are available in Fasolini (2014).

ena reflect the lower amount of rainfall recorded during these events $(40 \mathrm{~mm}$ in about 30-50 $\mathrm{h}$ in March and April 2013 events; $69 \mathrm{~mm}$ in $42 \mathrm{~h}$ in 28 February-2 March 2014 event).

These landslides had an average length of about $35 \mathrm{~m}$ and area varied from a minimum of $13 \mathrm{~m}^{2}$ to a maximum of almost $9000 \mathrm{~m}^{2}$, with an average of about $477 \mathrm{~m}^{2}$. The failure surface was mainly detected between 0.9 and $1 \mathrm{~m}$ from the ground level, generally in correspondence with the soilbedrock contact. $30 \%$ of these shallow landslides were triggered in vineyards, while an equal percentage of phenomena developed in woodlands or uncultivated areas. According to Cruden and Varnes' (1996) classification, most of the shallow landslides can be classified as roto-translational slides evolved into flows, with width / length ratio $>1$. Moreover, 


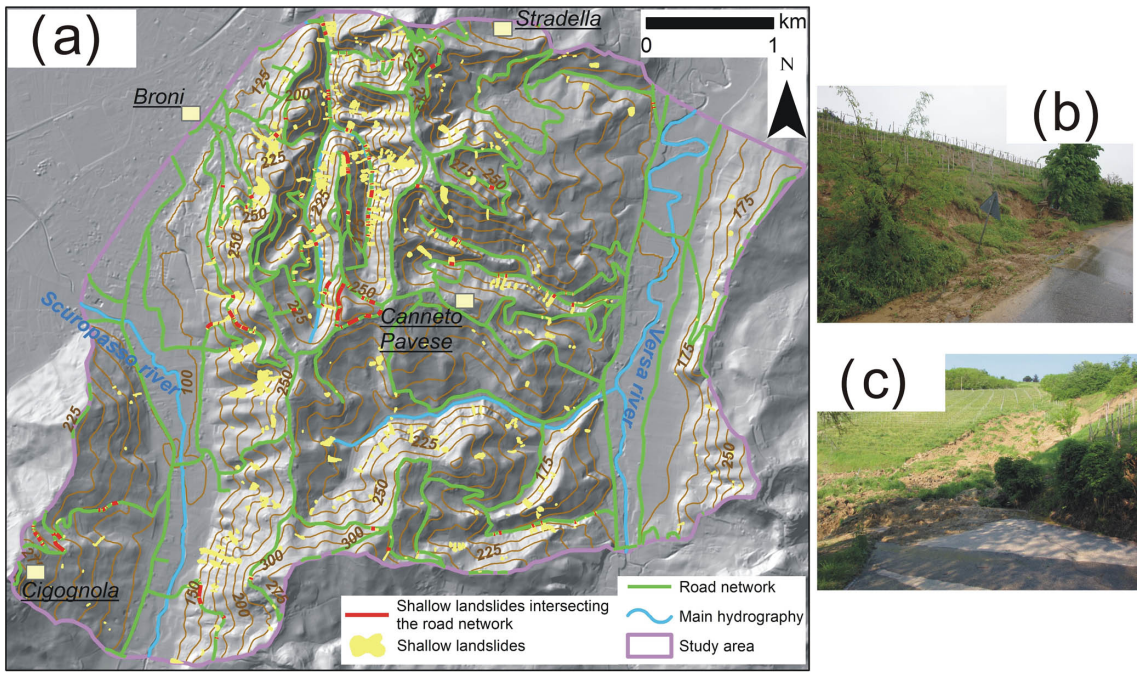

Figure 3. (a) Primary road network of the study area, with the shallow landslides events that occurred between 2009 and 2014 that affected these routes. This road network is composed of provincial and municipal roads (available from: Administration of Pavia Province and Infrastructure for Spatial Information in Lombardy (Lombardy Region geoportal: http://www.cartografia.regione.lombardia.it/geoportale, last access: 11 December 2017). (b) A shallow landslide (B2 type), triggered in correspondence of the road trench upstream of the route, that blocked the route. (c) A shallow landslide triggered in a slope cultivated with vineyards, whose mobilized materials destroyed completely a road trait downstream.

24 failures (5\% of the total number) were roto-translational slides affecting the trench in correspondence with a cut of a road. These phenomena were named as B2 type, according to the term used by Zizioli et al. (2013) and Persichillo et al. (2018).

The landslides significantly affected the road network, with severe damage (Fig. 3) i.e. the partial or complete destruction of road traits, debris accumulation and blockage, causing traffic restriction and the cut-off of villages and towns.

A detailed inventory map of the road sectors affected by shallow landslides in the study area was prepared and used as response variable of the model. The inventory map of affected road traits include all the sectors hit by the shallow landslides occurred in the study area during 27-28 April 2009, March/April 2013 and 28 February2 March 2014 rainfall events. For the 2009 event, colour aerial photographs at a resolution of $15 \mathrm{~cm}$ acquired immediately after the event were examined (Persichillo et al., 2017a). For 2013 event, affected road traits were identified by visual interpretation of Pleiades satellite images with a resolution of less than $1 \mathrm{~m}$ (Persichillo et al., 2017a). For 2014 event, slope failures and affected roads immediately after the event were detected through field surveys; the identified phenomena were mapped through a GPS tool, whose resolution is less than $2.5 \mathrm{~m}$.

In particular, $2.5 \mathrm{~km}$ of the principal road network was affected by shallow landslides in the last years. The 134 shallow landslides $(23 \%)$ hit roads, 24 failures ( $15 \%$ of the total number) were roto-translational slides affecting the trench of a cut realized for building a road. Instead, the remaining 90 phenomena $(85 \%)$ were shallow landslides triggered in slopes upstream the routes on cultivated or abandoned hillslopes. The length of the road sectors hit by a shallow landslide ranged between 2 and $94 \mathrm{~m}$.

\section{Methods}

\subsection{Development and test of the data-driven model}

\subsubsection{Predictor variables}

A data-driven methodology based on GAM was implemented for the assessment of roads that could be hit by shallow landslides. A schematic flow-chart of this methodology is shown in Fig. 4. Such a procedure is similar to that one proposed by Persichillo et al. (2017b) for the assessment of the shallow landslide susceptibility in different settings. In this paper, it was refined for the application to road susceptibility to landslides. In particular, different predictor variables and response variables were considered, according to their influence on the possible interaction between landslide mobilized materials and the road network located downstream.

In the model, 11 predictor variables were identified. Eight of these parameters were extracted by a $1 \mathrm{~m}$ resolution lidarderived Digital Elevation Model (DEM), through SAGA GIS (System for Automated Geoscientific Analyses; Olaya, 2004; Conrad et al., 2015). The DEM was available from the Italian Ministry of Environment and Protection of the Land and Sea, following the realization of the Piano Straordinario di Teleril- 

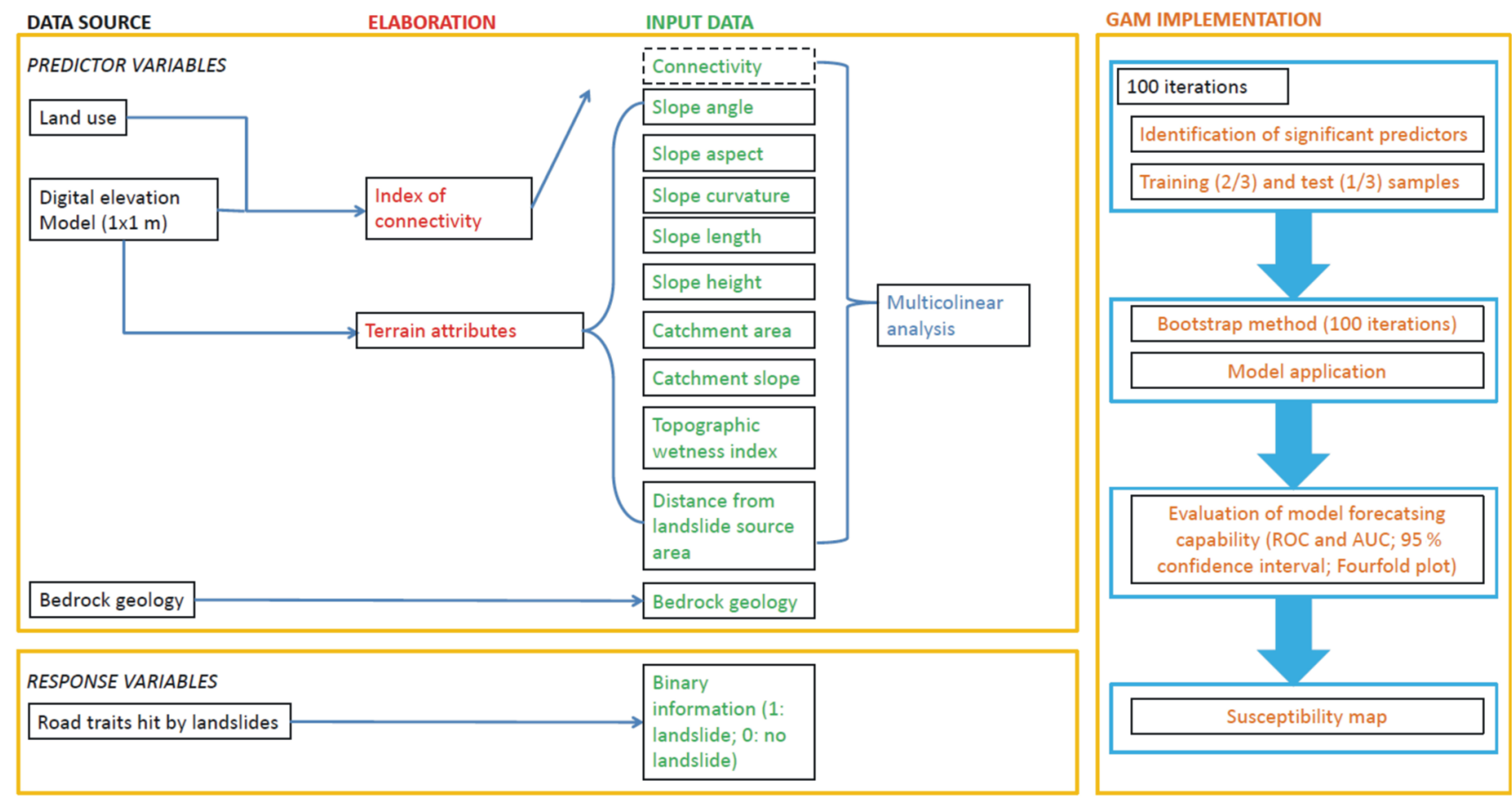

Figure 4. Flow-chart containing the scheme for the implementation of the proposed model.

evamento Ambientale (Extraordinary Plan of Environmental Remote Sensing - PST-A). These attributes were slope angle (SL), aspect (ASP), curvature (CURV), slope length (LEN), slope height (HEI), catchment area (CA), catchment slope (CS) and topographic wetness index (TWI).

SL, ASP and CURV were calculated through Zevenbergen and Thorne (1987)' approximations. SL strongly controls the velocity of the material mobilized by a shallow landslide, thus its capacity of travelling for long distances from the source areas (Fannin and Wise, 2001; Catani et al., 2013; Fathani et al., 2017). ASP influences the soil moisture and the vegetation growth, that can have a key role on the susceptibility of a slope to shallow failures (Van Westen et al., 2008; Jaiswal et al., 2010a). CURV influences the amount of water runoff, the rate of underground water movement and the potential rates of sedimentation and erosion (Dai et al., 2002; Kritikos and Davis, 2015).

LEN and HEI are key parameters for the estimation of the distance travelled by a landslide from its source area and of the velocity of the displaced material (Bathurst et al., 1997; Chau et al., 2004; Martinovic et al., 2016). LEN is the distance from the point of origin of overland flow to the point where either the slope gradient decreases enough for deposition to start, or runoff waters are streamed into a channel (Wischmeier and Smith, 1978). This parameter is useful to predict zones where the soil deposition is predominant (Winchell et al., 2008). HEI represented the elevation difference between the source area of a shallow landslide and the bottom of the hillslope where this failure occurred.
Multiple-flow direction algorithm (Quinn et al., 1991) was used to obtain CA and CS. Multiflow direction algorithm distributed the water flow to all neighbouring downslope cells weighted according to slope angle, avoiding the flow concentration to particular lines sometimes unrealistic. In the case of planar and concave hillslopes, as the ones present in the study area, the partitioning of the flow provided by the use of the multiflow direction algorithm was consistent to the real situation (Seibert and McGlynn, 2007).

CA is used as a proxy for soil moisture and soil depth, thus for the potential amount of materials that can be mobilized by the shallow landslide and that can reach an infrastructure (Brenning et al., 2015). CS influences the destabilizing forces upstream that can provoke the development of a landslide (Brenning et al., 2015; Persichillo et al., 2017b). TWI highlights the water fluxes along the slopes and the position of the accumulation points in a catchment (Seibert et al., 2007).

Along with the DEM-derived predictor variables, the Euclidean distance from the shallow landslide source area (DIST) was calculated, considering the shortest distance between the landslide source area and a considered road trait. The choice of an Euclidean distance was consistent to the types of slope failures present in the study area. The shallow landslides did not follow established paths of the flow direction on the hillslopes where they occurred. Moreover, they were not channelled, as in the case of typical debris flows. Furthermore, the distance calculated along the flow direction was not considered to avoid redundancy with the 
parameter of sediment connectivity. In fact, sediment connectivity already took into account the shortest paths along the flow direction in its downslope component (Cavalli et al., 2013; Crema and Cavalli, 2018). DIST parameter is consistent with slopes of homogeneous gradient, aspect and curvature and is important in understanding the capacity of the mobilized material to travel along a slope and to reach a route located downstream (Bil et al., 2014; Brenning et al., 2015). The source area of each slope failure was extracted through Galve et al. (2015)'s procedure, selecting $25 \%$ of the landslide area in correspondence to the highest elevations.

Bedrock geology (GEO) was also considered as predictor. GEO influences the geomechanical, geotechnical, rheological and hydrological properties of the soil, which have effects on the runout of a landslide (Hungr, 1995; Pastor et al., 2014). GEO was obtained from the geological map of the studied catchment, realized by the Department of Earth and Environmental Sciences of University of Pavia through field surveys.

Different authors (Budetta, 2004; Jaiswal et al., 2010a, b, 2011; Quinn et al., 2010; Michoud et al., 2012; Bil et al., 2014, 2017; Ramesh and Anbazhagan, 2015; Pellicani et al., 2017; Postance et al., 2017) had already used some of the previously described predictors in different data-driven model aiming to assess roads susceptible to being hit by shallow landslides. Until now, sediment connectivity has not been considered yet. Tarolli and Sofia (2016) and Persichillo et al. (2018) analyzed two different hilly and mountainous catchments, located in western USA and northeastern Oltrepò Pavese, respectively, in order to highlight potential connections between a road network and the sediment delivery. The works both quantified the sediment connectivity using the index of connectivity (IC), that allows the evaluation of the potential connection between hillslopes and features, which act as targets for transported sediments based only on the morphological and topographical characteristics and the vegetation cover of a territory. These works highlighted that the segments of the road network, which can act as a storage area for the sediments mobilized by a phenomenon upstream to the road, are those ones located in correspondence of zones characterized by high IC values. This aspect testifies how slope instability phenomena can actively deliver sediment to particular portions of a road network, producing damage provoked by the impact of the mobilized materials on the infrastructure (Sidle et al., 2014; Klose et al., 2015). Persichillo et al. (2018) demonstrated that, in two catchments of Oltrepò Pavese, the road sectors hit by the materials mobilized by shallow landslides that occurred upstream are the ones located close to slopes characterized by the lowest or the highest values of sediments connectivity along the entire catchment. In order to verify the potential influence of this parameter in discriminating the susceptible road sectors, an index of sediment connectivity within the predictor variables of the model was inserted.
The index of sediment connectivity (IC), defined by Borselli et al. (2008), evaluates the potential connection between hillslopes and features that act as targets or storage areas (sinks) for mobilized sediments (e.g., channels, basin outlet, lakes or road networks). In the proposed model, IC, calculated according to the approach of Cavalli et al. (2013), was implemented for a better characterization of surface processes and properties and to exploit a high-resolution DEM. For further details on the changes introduced in the IC calculation following this scheme, we refer to Cavalli et al. (2013) and Crema and Cavalli (2018).

IC is calculated according to Eq. (1) combining the upslope $\left(D_{\text {up }}\right)$ and downslope $\left(D_{\mathrm{dn}}\right)$ components of connectivity, respectively.

IC $=\log _{10} \frac{D_{\text {up }}}{D_{\mathrm{dn}}}$

IC can have values in the range of $[-\infty,+\infty]$, with connectivity increasing for larger IC values (Cavalli et al., 2013). IC was calculated through the stand-alone application SedInConnect 2.3 (Crema and Cavalli, 2018).

In the calculation of IC, both the $D_{\text {up }}$ and $D_{\mathrm{dn}}$ depend on a weighting factor $(W)$ (Eqs. 2, 3):

$$
\begin{aligned}
D_{\text {up }} & =\overline{W S} \sqrt{A} \\
D_{\mathrm{dn}} & =\sum_{i} \frac{d_{i}}{W_{i} S_{i}},
\end{aligned}
$$

where $S$ is the average slope gradient of the upslope contributing area, $A$ is the upslope contributing area, $d_{i}$ and $S_{i}$ are the length of the flow path and the slope gradient for the $i$ th cell, respectively.

$W$, intended to model the impedance to sediment fluxes, was extracted in two different ways:

1. according to the linear formulation of $W$ (Eq. 4) as a function of land use:

$W_{\text {lin }}=1-n$,

where $n$ is the Overland Flow Manning's $n$ Roughness Value, which depends on the land use type (Table 1);

2. according to the non-linear approach proposed by Gay et al. (2015) and Kalantari et al. (2017) as a function of the morphological properties and of the land use characteristics (Eq. 5):

$$
W_{\mathrm{nl}}=\frac{1}{1+e^{-0.5\left(x-x_{0}\right)}}\left(1-\frac{R_{i}}{R_{i \max }}\right),
$$

where $R_{i}$ is the roughness index dependent on the surface morphology variability (Cavalli et al., 2008; Cavalli and Marchi, 2008), $R_{i \max }$ is the highest value of $R_{i}$ in the study area and $x_{0}$ is the midpoint of the distribution function of $R_{i}$ in an area. 
Table 1. Overland flow Manning's $n$ Roughness Values assigned to each class of land use maps available for the calculation of $W_{\text {lin }}$ factor.

\begin{tabular}{lr}
\hline Land use classes & Manning's $n(-)$ \\
\hline Woodlands & 0.40 \\
Uncultivated areas & 0.35 \\
Grasslands & 0.25 \\
Orchards/arable areas/vineyards & 0.20 \\
Bare soil & 0.05 \\
Urban areas & 0.02 \\
\hline
\end{tabular}

According to the different methods of calculation, IC distribution changes (Kalantari et al., 2017). In the considered case study, IC was calculated with both approaches, producing two IC maps $\left(\mathrm{IC}_{\text {lin }}\right.$ obtained implementing $W_{\text {lin }}, \mathrm{IC}_{\mathrm{nl}}$ obtained implementing $W_{\mathrm{nl}}$ ), inserted alternatively in the model for the assessment of the roads susceptible to shallow landslides.

For each trait of the road network analyzed, the value of each assigned predictor corresponded to the one of the slope immediately upstream the road trait, where a landslide that could hit this sector could be triggered. This is consistent with the features of the slopes where shallow landslides occurred in the past in the study area. In fact, from the source area to the accumulation zone of each landslide, the failed slopes kept similar morphological and hydrological features, in terms of slope angle, exposition, curvature and hydrological features (Bordoni et al., 2015; Persichillo et al., 2017b). Maps of the predictor variables were produced for the study area at a resolution of $1 \mathrm{~m}$, as the input DEM.

\subsubsection{Response variable}

The response variable corresponded to the inventory of the road traits hit by sediments mobilized by shallow landslides during events that occurred between 2009 and 2014. In the inventory map binary information was inserted; a value equal to 0 was assigned to the road segments not affected by a shallow landslide, while a value of 1 was assigned to each hit road trait. The resolution of this map was set to that of the predictor variable $(1 \mathrm{~m})$. The inventory maps referred to the primary road network of the study area, composed of provincial and municipal routes. This was considered because this network contains the most affected road sectors, in terms of economic damage and indirect losses (restriction of traffic, cut-off of villages due to the blockage of roads).

\subsubsection{Implementation of GAM model}

The data-driven methodology developed for assessing susceptible roads was based on GAM. GAM is an extension of the Generalized Linear Model (GLM), in which the linear function is replaced by an empirically fitted smooth function that allows fitting the data in the more likely functional form (Hastie and Tibshirani, 1990; Goetz et al., 2011). GAM uses a link function to relate the mean $(\mu)$ of the response variables (probability that a road sector could be hit by a landslide) and the sum of smooth functions of the predictor variables (Jia et al., 2008) (Eq. 6):

$g(\mu)=\sum_{i=1}^{n} f_{i}\left(x_{i}\right)$

where $g$ is the link function and the $f_{i}$ is the smooth function (typically splines), each dependent on a single predictor variable, $x_{i}$, chosen in a set of $n$ variables $x_{i} \ldots x_{n}$.

GAM was implemented through a "gam" package of $\mathrm{R}$ software (Hastie, 2013). Starting from null model, each predictor variable can be included in the GAM model as linear (untransformed), non-linear (non-parametrically transformed with two equivalent degrees of freedom), or not included in the model. For the selection of the explanatory variables, we used the "step.gam" command of the R package "gam". The variables were selected allowing both directions in the step-wise search, using the option direction = "both" in issuing the step.gam command. The selected "best" model is the one that minimizes the Akaike Iteration Criterion (AIC).

The adopted procedure was composed of the following steps. The first step was the application of a multi-collinear analysis between the numerical predictor variables. Multicollinearity verifies when some predictor variables are linearly correlated among them to avoid redundancy that could affect the numerical stability (Farrar and Glauber, 1967). The condition indexes of the matrix of the independent variables was calculated. Variables featuring an index higher than 30 were considered not independent, thus they were excluded from the analyses to reduce collinearity (Belsley et al., 1980).

In the second step, a database formed of an equal number of road pixels affected or not affected by shallow landslides was implemented in order to avoid the over-estimation of non-landslide areas, which are much wider than landslide ones (Dai and Lee, 2002; Ayalew and Yamagishi, 2005; Persichillo et al., 2017b). Then this database was subdivided into training and test sets. The training set, corresponding to twothirds of the dataset, was used to fit the model. Whereas the test set, forming of the remnant third of the dataset, was used to verify the accuracy of the model. Training and test sets were randomly selected for 100 times according to a bootstrap procedure. The most frequent predictor variables (selected at least 80 times by the bootstrap procedure) were used to build the final susceptibility model. Moreover, linear and non-linear predictors were identified according to the higher percentage of selection of each parameter.

Model forecasting capability constituted the third step of model scheme. A 100-fold repetition of the holdout method for regression with a binary response (McLachlan, 1992; Molinaro et al., 2005; Maindonald and Braun, 2010), consisting of a random sub-sampling of different training and 


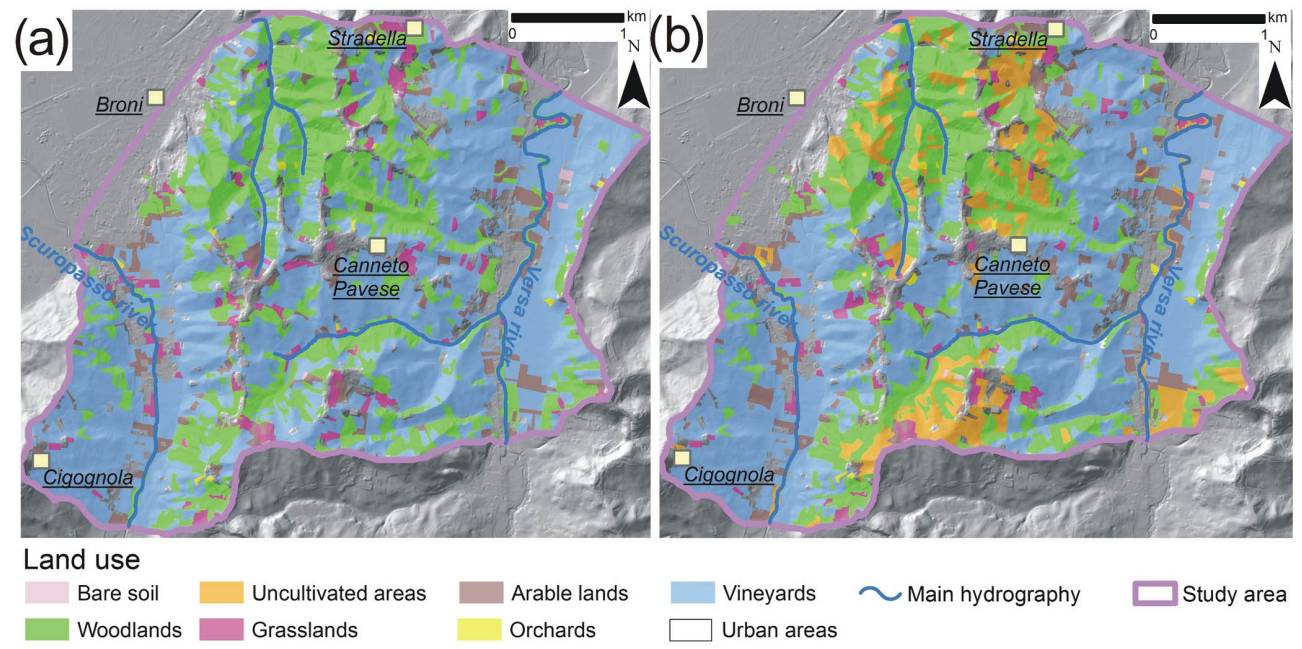

Figure 5. Potential land use scenarios used for the assessment of road susceptibility to shallow landslides in the study area, together with the 1980 land use distribution (Fig. 2c): (a) Scenario 3, correspondent to the transformation of actual uncultivated areas in woodlands; (b) Scenario 4, correspondent to an increase in abandoned areas similar to those in 1980-2015 period.

test sets, in the proportion of two-thirds for testing and onethird for the test, was implemented. The accuracy calculated for these iterations in all training and test sets was averaged to obtain its overall value. The considered training and test sets were the ones created through the 100 bootstrap model selection. The area under the Receiver Operating Characteristic (ROC) curve (AUC) (Hosmer and Lemeshow, 2000) was computed to evaluate the model's ability to discriminate affected road sectors, furnishing a further measure of the accuracy of the model. The AUC can take values from 0.5 (no discrimination) to 1.0 (perfect discrimination; Spitalnic, 2004). Moreover, the mean value and the bootstrap $95 \%$ confidence intervals of the 100 AUC obtained from the 100-fold bootstrap procedure for the overall accuracy of the model were calculated.

Furthermore, the 100 fitted bootstrap models were used to extend the prediction to the whole road sectors to obtain the distribution of probability. Thus, the map of the susceptibility to be hit by shallow landslides was obtained from the mean values of each bootstrap distribution of 100 probability values. Also a prediction uncertainty was associated with to each estimated probability was estimated through the calculation of by calculating the bootstrap $95 \%$ confidence intervals of the susceptibility. Different classes of probability susceptibility were created, subdividing into four intervals the probability values in the susceptibility map: low $(0<p \leq 0.25)$, medium-low $(0.25<p \leq 0.50)$, medium-high $(0.50<p \leq 0.75)$ and high $(0.75<p \leq 1)$.

The number of true positives (TP), true negatives (TN), false positives (FP) and false negatives (FN) was further obtained by comparing the susceptibility map with the response variable map used to build the model (Jollifee and Stephenson, 2003). For making this comparison, susceptibility values were classified as a binary variable: 1 was assigned to values higher than 0.5 (modelled pixel hit by a landslide), while 0 was assigned to values lower than 0.5 (modelled pixel not affected by a landslide).

Susceptibility was calculated considering a spatial resolution of $1 \mathrm{~m}$, as the input predictors, and for a buffer of $5 \mathrm{~m}$ from the middle of each road sector. The chosen buffer of $5 \mathrm{~m}$ was consistent with the size of the roads present in the study area. These roads had similar sizes, with a width of the roadway ranging between 3.5 and $5 \mathrm{~m}$.

To assess the effect of considering IC in modelling the susceptibility, three models were produced and compared: Model (1) using all the predictor variables except for the IC; Model (2) considering all the predictors with $\mathrm{IC}_{\text {lin }}$; Model (3) considering all the predictors with $\mathrm{IC}_{\mathrm{n}}$.

\subsection{Change in susceptibility according to different land use scenarios}

IC depends on the morphological features and on the land use of hillslopes, due to the presence of $W$ factor. On the hypothesis that morphological features does not change, IC maps were created using particular land use distribution, representative of potential situations that could characterize the study area.

Aside from the current scenario used for building the susceptibility models at this time, another three scenarios were considered. The second scenario (Scenario 2) consists of the 1980 land use map, where the widest extension of cultivated vineyards was reached (Fig. 2c). Thus, this scenario represents the possible distribution of vineyards in the case of a complete recovery of the abandoned areas since the 1980s.

The third scenario (Scenario 3) corresponded to the actual scenario, with an interruption in the increase of aban- 

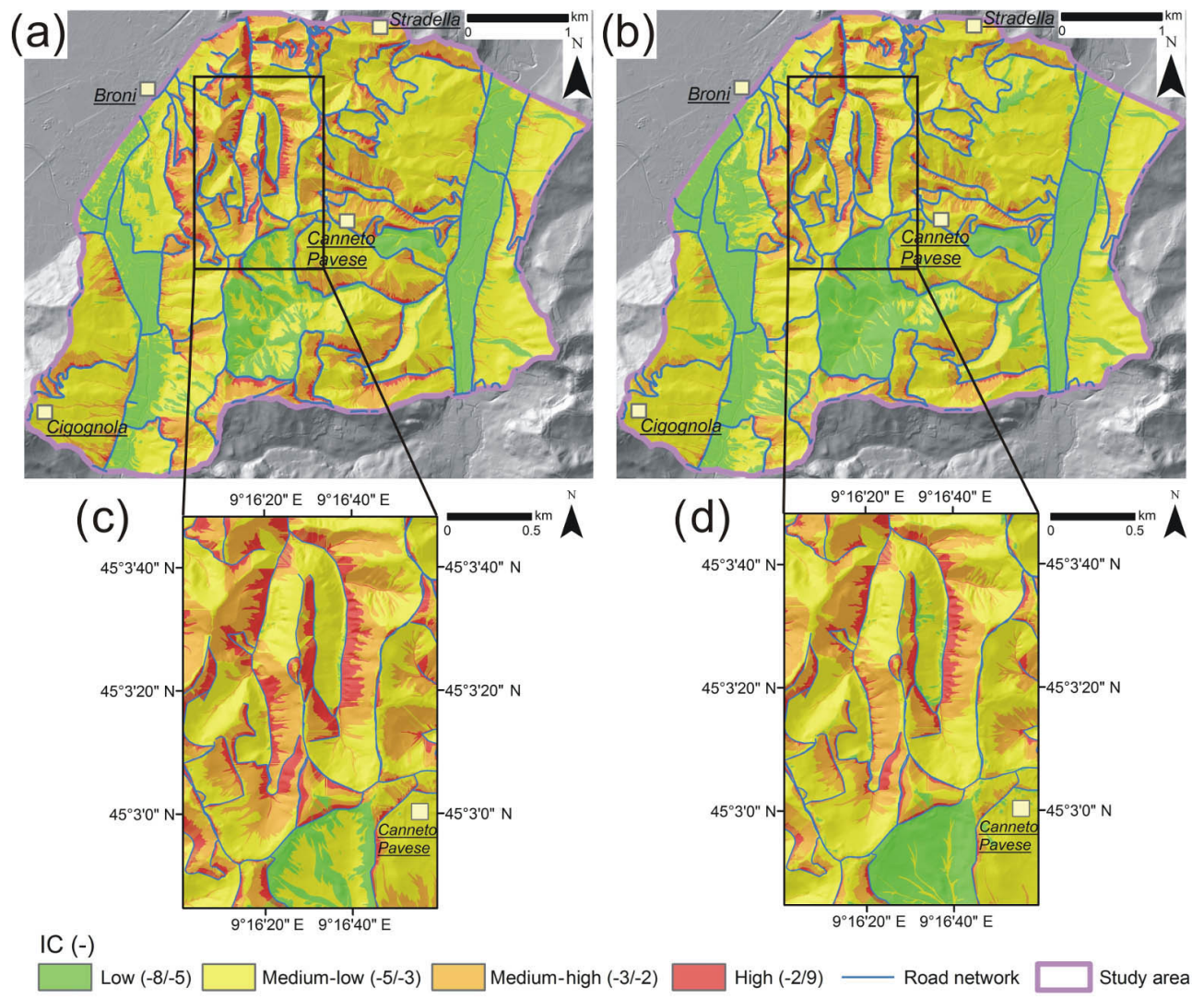

Figure 6. Actual (2015) IC maps corresponding to the linear calculation of the index since $W_{\text {lin }}$ (a) and to the non-linear calculation of the index since $W_{\mathrm{nl}}(\mathbf{b})$. A detail of the northern sector of the study areas is reported for $\mathrm{IC}_{\text {lin }}(\mathbf{c})$ and $\mathrm{IC}_{\mathrm{nl}}$ (d) maps.

doned areas without the recovery of the previously cultivated slopes. According to this, uncultivated areas completely disappear and they convert into woodlands (Fig. 5a). This scenario is consistent with the new land use management policies that were developed at the municipal level in the study area, aiming at regulating the diffusion of uncultivated areas (Rural Police Regulation, 2008; Persichillo et al., 2017a).

The fourth scenario (Scenario 4) corresponded to a further increase in the abandonment of cultivated grapevines (Fig. 5b). According to this, actual uncultivated areas transform into woodlands, while further uncultivated ones develop in correspondence of actual vineyards. The slopes where abandonment was supposed are the currently cultivated slopes with similar morphological features (slope angle higher than $15^{\circ}$ ) to the abandoned areas in the period 1980-2015. The increase in abandoned areas was kept equal to $22 \%$, as occurred from the period 1980-2015.

Different IC scenarios were then created using these land use distributions and they were inserted in GAM model for assessing the susceptibility change of road traits in function of this parameter. Other morphological and hydrological input predictors were kept steady. The model used for these reconstructions corresponded to the one that had the best predictive performance considering the actual situation.

\section{Results}

\subsection{Map of IC reconstructed through linear and non-linear methodology}

The distribution of IC for the actual conditions, reconstructed through the linear $\left(\mathrm{IC}_{\text {lin }}\right)$ and non-linear $\left(\mathrm{IC}_{\mathrm{nl}}\right)$ calculation of the $W$ factor, was analyzed (Fig. 6). In the study area, $\mathrm{IC}_{\text {lin }}$ ranged between -7.00 and 1.75 , while $\mathrm{IC}_{\mathrm{nl}}$ values ranged between -4.20 and 2.23 (Fig. 7). The average value of IC distribution was -3.17 for $\mathrm{IC}_{\text {lin }}$ and -3.57 for $\mathrm{IC}_{\mathrm{nl}}$, while the standard deviation was similar for both the distributions ( 0.72 and 0.65 , respectively). The map obtained with the linear implementation of $W$ in IC calculation showed values averagely higher than the ones obtained with the non-linear $W$ methodology in the corresponding sectors (Fig. 6).

In these analyses, IC values were classified into four classes (low, medium-low, medium-high and high), by identifying classes limits that best grouped similar values and maximized the differences between classes using the Jenks natural breaks (Jenks, 1967) following the approach used in similar contexts by Surian et al. (2016), Tarolli and Sofia (2016) and Tiranti et al. (2016). 
Table 2. Frequencies (in percentages) of explanatory variables (both linear and non-linear) selected by 100-fold bootstrap procedure. The explanatory variables selected by 100 -fold bootstrap procedure with an absolute frequency greater or equal than $80 \%$ are highlighted in bold. In the brackets, the frequencies (in \%) of selection of each variable as linear or non-linear is shown. The italic number corresponds to the frequency of the selected function connected to each variable. SL: slope angle; ASP: aspect; CURV: curvature; LEN: slope length; HEI: slope height; CA: Catchment area; CS: Catchment slope; TWI: topographic wetness index; DIST: distance from the source area of a shallow landslide; GEO: bedrock geology; IC: index of connectivity.

\begin{tabular}{|c|c|c|c|c|c|c|c|c|c|c|c|}
\hline Model & SL & ASP & CURV & LEN & HEI & $\mathrm{CA}$ & $\mathrm{CS}$ & TWI & DIST & GEO & IC \\
\hline $\begin{array}{l}1 \\
\text { (Lin.-not Lin.) }\end{array}$ & $\begin{array}{r}97 \\
(95-2)\end{array}$ & $\begin{array}{r}2 \\
(0-2)\end{array}$ & $\begin{array}{r}87 \\
(41-46)\end{array}$ & $\begin{array}{r}36 \\
(36-0)\end{array}$ & $\begin{array}{r}88 \\
(45-43)\end{array}$ & $\begin{array}{r}56(56-0) \\
(56-0)\end{array}$ & $\begin{array}{r}100 \\
(0-100)\end{array}$ & $\begin{array}{r}85 \\
(14-71)\end{array}$ & $\begin{array}{r}100 \\
(0-100)\end{array}$ & 100 & - \\
\hline $\begin{array}{l}2 \\
\text { (Lin.-not Lin.) }\end{array}$ & $\begin{array}{r}97 \\
(95-2)\end{array}$ & $\begin{array}{r}18 \\
(12-6)\end{array}$ & $\begin{array}{r}87 \\
(41-46)\end{array}$ & $\begin{array}{r}19 \\
(19-0)\end{array}$ & $\begin{array}{r}88 \\
(45-43)\end{array}$ & $\begin{array}{r}66 \\
(66-0)\end{array}$ & $\begin{array}{r}100 \\
(0-100)\end{array}$ & $\begin{array}{r}85 \\
(16-69)\end{array}$ & $\begin{array}{r}100 \\
(0-100)\end{array}$ & 100 & $\begin{array}{r}100 \\
(5-95)\end{array}$ \\
\hline $\begin{array}{l}3 \\
\text { (Lin.-not Lin.) }\end{array}$ & $\begin{array}{r}97 \\
(95-2)\end{array}$ & $\begin{array}{r}18 \\
(11-7)\end{array}$ & $\begin{array}{r}87 \\
(41-46)\end{array}$ & $\begin{array}{r}19 \\
(19-0)\end{array}$ & $\begin{array}{r}92 \\
(53-39)\end{array}$ & $\begin{array}{r}65 \\
(65-0)\end{array}$ & $\begin{array}{r}100 \\
(0-100)\end{array}$ & $\begin{array}{r}95 \\
(12-83)\end{array}$ & $\begin{array}{r}100 \\
(0-100)\end{array}$ & 100 & $\begin{array}{r}100 \\
(2-98)\end{array}$ \\
\hline
\end{tabular}

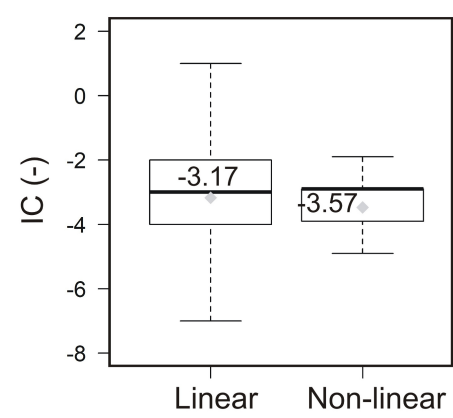

Figure 7. Box-plot of IC values distribution for the actual scenario (2015), for the linear and non-linear calculation of the index.

The $\mathrm{IC}_{\text {lin }}$ map highlighted that the northern and western parts of the catchment were characterized by medium-high and high connectivity (Fig. 6a). All the slopes with a high gradient (generally higher than $15^{\circ}$ ) presented medium-high and high connectivity features. Highest values were reached in road trenches with limited slope height (lower than $20 \mathrm{~m}$ ) and at the bottom of hillslopes characterized by high slope angle (higher than $15-20^{\circ}$ ) and by slope height in the order of 35-70 m.

Instead, the $\mathrm{IC}_{\mathrm{nl}}$ map indicated lower connectivity in all the sectors of the study area (Fig. 6b). Where the $\mathrm{IC}_{\text {lin }}$ map showed a wide diffusion of slopes with medium-high and high connectivity, $\mathrm{IC}_{\mathrm{nl}}$ highlighted especially medium-low and low sediment connectivity (Fig. 6b). Only a few areas close to road segments were characterized by high connectivity (Fig. 6d). These sectors corresponded to the road trenches characterized by a slope height lower than $20 \mathrm{~m}$; both reconstructions showed low and medium-low connectivity where plain areas or hillslopes with slope angle lower than $10^{\circ}$ are present (Fig. 6).

\subsection{GAM models implementation}

\subsubsection{Selection of the explanatory variables}

Three GAM models were tested on the basis of the different set-up of the input predictors. The first phase was the selection of the variables to introduce in each model. All the predictors were not collinear so all these were inserted in the modelling. For each model, the variables whose selection frequency was higher than $80 \%$ in the 100 -fold bootstrap procedure were selected. The selected variables were the same ones for all three models, with similar selection frequency (Table 2). IC was taken into account only in Model 2 and Model 3, and then consequentially selected in both these models (Table 2). Besides IC (having a selection frequency equal to $100 \%$ in both Models 2 and 3), the variables selected are the following (Table 2): SL (97\%), CURV (87\%), HEI (88-92\%), CS (100\%), TWI (85-95\%), DIST (100\%) and GEO $(100 \%)$ in all the three models. ASP, LEN, and CA were excluded from all the models. Among these variables, only CA had a quite high frequency of selection (56$66 \%$ ), but it fell under the defined threshold (Table 2). The selected continuous explanatory variables (all the predictors, except GEO) were distinguished into linear or non-linear, on the basis of the higher percentage of selection obtained in the bootstrap procedure. SL and HEI were chosen as linear, while CURV, CS, TWI, DIST and IC were selected as nonlinear (Table 2). Despite the different types of calculation of the IC implemented in Model $2\left(\mathrm{IC}_{\mathrm{lin}}\right)$ and in Model $3\left(\mathrm{IC}_{\mathrm{nl}}\right)$, this variable was evaluated as significant in both this model, with a frequency of $100 \%$. Moreover, IC was chosen as a non-linear variable in both these models (Table 2).

\subsubsection{Predictive performance and susceptibility maps of the models}

Model 1, that did not consider IC, is characterized by a fair predictive capability. In fact, AUC of the training and the test sets of this model were equal to 0.71 and 0.70 , respec- 
Table 3. Mean and standard deviation of accuracy for the training sets, the test sets and the final application of the model to the entire study area.

\begin{tabular}{rrrrrrr}
\hline Model & $\begin{array}{r}\text { Mean accuracy } \\
\text { of training } \\
\text { sets }(-)\end{array}$ & $\begin{array}{r}\text { Standard deviation } \\
\text { of accuracy on } \\
\text { training sets }(-)\end{array}$ & $\begin{array}{r}\text { Mean accuracy } \\
\text { on test } \\
\text { sets }(-)\end{array}$ & $\begin{array}{r}\text { Standard deviation } \\
\text { of accuracy on } \\
\text { test sets }(-)\end{array}$ & $\begin{array}{r}\text { Mean AUC } \\
\text { of the model } \\
(-)\end{array}$ & $\begin{array}{r}95 \% \text { confidence } \\
\text { interval of AUC of } \\
\text { the model (-) }\end{array}$ \\
\hline 1 & 0.71 & 0.01 & 0.70 & 0.01 & 0.74 & $0.73-0.75$ \\
2 & 0.90 & 0.01 & 0.90 & 0.01 & 0.94 & $0.93-0.95$ \\
3 & 0.82 & 0.01 & 0.82 & 0.01 & 0.83 & $0.82-0.84$ \\
\hline
\end{tabular}
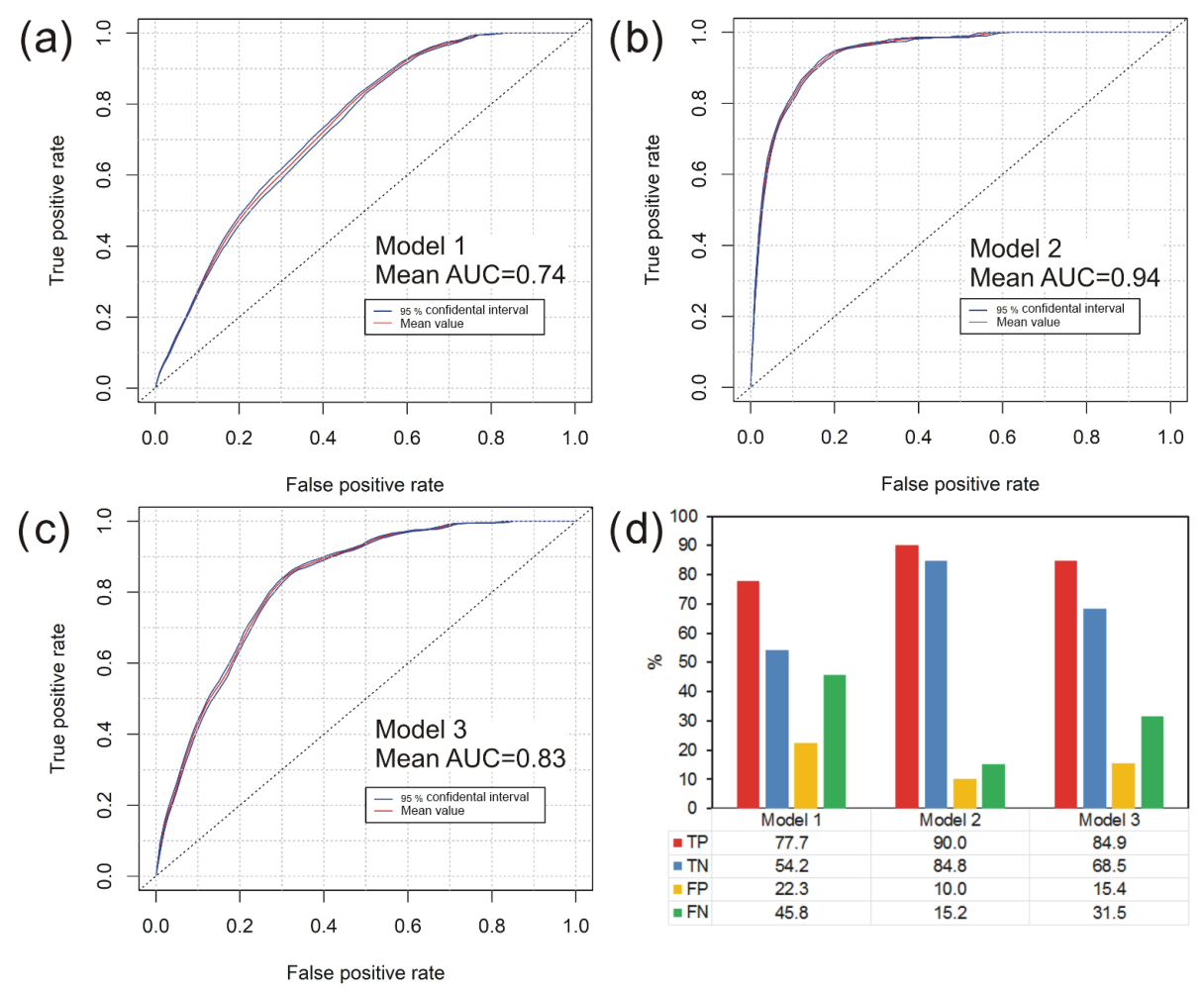

Figure 8. $95 \%$ bootstrap confidence bands of ROCs: (a) Model 1; (b) Model 2; (c) Model 3. (d) Percentage of true positives (TP), true negatives (TN), false positives (FP) and false negatives (FN) of the different models.

tively (Table 3). AUC of the final susceptibility map produced with Model 1 was similar to those of training and test sets $(0.74$; Table 3$)$. However, the predictive capability increased whether or not the IC parameter was added among the predictor variables. In particular, AUC of training and test sets increased until 0.82 for Model 3, that also considered also $\mathrm{IC}_{\mathrm{nl}}$. For this model, AUC of the final susceptibility map was of 0.83 , with an increase of 0.09 with respect to Model 1 (Table 3). A better effectiveness was reached if $\mathrm{IC}_{\text {lin }}$ was taken into account (Model 2). AUC of training and test sets of Model 2 reached values of 0.90, while AUC of the final susceptibility map was of 0.94 . According to Spitalnic (2004), a model with similar predictive performances can be classified as excellent.

Table 3 also highlighted very low values of standard deviation in AUC of training and test sets of each model that were maintained equal to 0.01 . This confirmed the reliability of the procedure used to build up the different models.

Furthermore, the bootstrap $95 \%$ confidence intervals of AUCs were every 0.02 . This result is also confirmed by the very narrow bootstrap $95 \%$ confidence bands of ROC curves (Fig. 8a, b, c). The maps showing the bootstrap $95 \%$ confidence intervals of the probability for each road trait to be hit by a shallow landslide are illustrated in Fig. 8. As confirmed by the low values of the confidence intervals remaining lower than 0.25 , the spatial variability of this probability is generally low in the entire road network of the study area for each model (Fig. 9).

The predictive capability of the models were also evaluated by computing the values of the four indexes of a fourfold plot. TP and TN were significantly higher in Model 2 than Model 1 and 3, while FP and FN were significantly 
lower in the same model that the others (Fig. 8d). TP and TN reached values of 90.0 and $84.8 \%$ in Model 2, respectively. These values highlighted an increase of $5.1-13.7 \%$ respect to Model 3 and of $13.3-30.6 \%$ respect to Model 1 . The highest effectiveness of Model 2 was confirmed also by the lowest values of FP and FN (10.0 and $15.2 \%$, respectively), that were lower of 5.4-35.8\% than Model 1 and Model 3 (Fig. 8d).

The susceptibility maps for the road network extracted by GAM models are in Fig. 10. Model 1 classified $46.9 \%$ of the road network in medium-high and high susceptibility classes. This percentage is significantly higher than those obtained for Model 2 and Model 3 (Fig. 11). The widespread diffusion of high susceptibility areas in Model 1 also explains the high values of FP measured for this model.

Model 2 and Model 3, also considering IC within predictors, classified a lower percentage of the road network in medium-high and high susceptibility classes which are overall of 15.4 and $18.3 \%$, respectively (Fig. 11). The number of high susceptible road traits of Model 3 seems overestimated in respect to the real situations, as demonstrated by the higher FP and FN than Model 2 (Fig. 8d). Model 2 presented a higher predictive performance than the other models, as confirmed by the quantitative indexes calculated for GAM model. It classified $15.4 \%$ of the road network of the study area in medium-high and high susceptibility classes and the remnant $85.6 \%$ in low and medium-low classes (Fig. 11). All the susceptibility maps classified as more susceptible the road sectors located below slopes of SL higher than $20^{\circ}$, HEI lower than $50 \mathrm{~m}$, catchment slope between 28 and $30^{\circ}$ and DIST in the range of 40-100 m. Moreover, Model 2 and Model 3 discriminated those road traits as more susceptible in correspondence with areas of medium-high and high IC, generally higher than -3 , regardless of the land use which covered the slope above the road.

\subsection{Susceptibility maps according to different land-use scenarios}

The assessment of the predictive capabilities of the GAM models related to the actual scenarios revealed that Model 2 was the best one. This model took into account for several morphological and hydrological features of the slopes upstream the road sectors and the sediment connectivity, evaluated according to the linear modelling of IC parameter. Due to the importance of considering IC distribution in the evaluation of the routes that could be affected by shallow landslides, susceptibility scenarios were created varying IC maps input according to three defined scenarios of land use distribution hypothesized for the study area (Scenario 2, Fig. 2c; Scenario 3, Fig. 5a; Scenario 4, Fig. 5b). In fact, IC may change as a function of the change in the distribution of $W$ factor used in the calculation of this index.

Figure 12 illustrates the influence of different land use scenarios on IC. Its spatial distribution did not seem to be af-
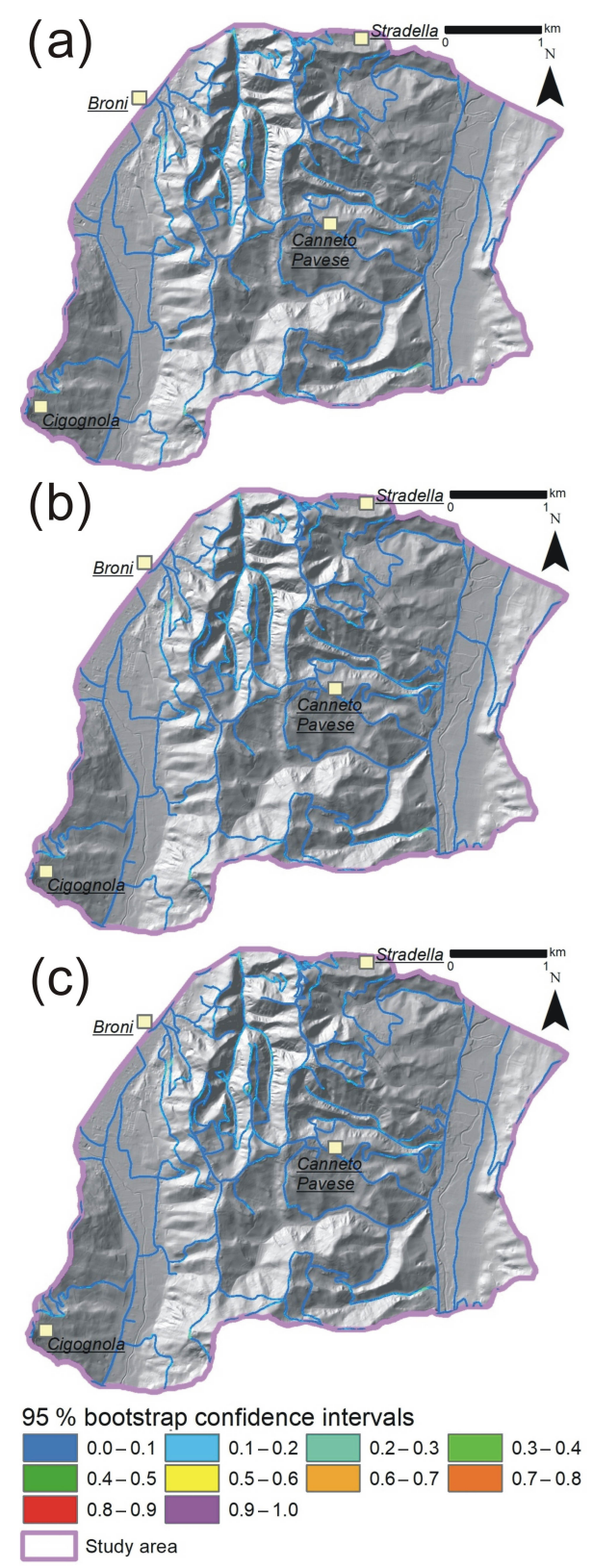

Figure 9. Maps of the amplitude of $95 \%$ bootstrap confidence intervals of the probability associated to each pixel of the studied area: (a) Model 1; (b) Model 2 and (c) Model 3.

fected by land use changes presented in the considered scenarios. The connectivity of a particular hillslope kept approximately equal to the actual scenario. This was also confirmed by the mean and the standard deviation of the distribution of IC values in the study area, which remained equal to $-3.20 /-3.17$ and $0.72 / 0.74$, respectively.

The similar maps of $\mathrm{IC}_{\text {lin }}$ obtained for the different land use maps implicated that the susceptibility distribution along the road network did not change significantly for the different considered scenarios (Fig. 13). Compared to the sus- 

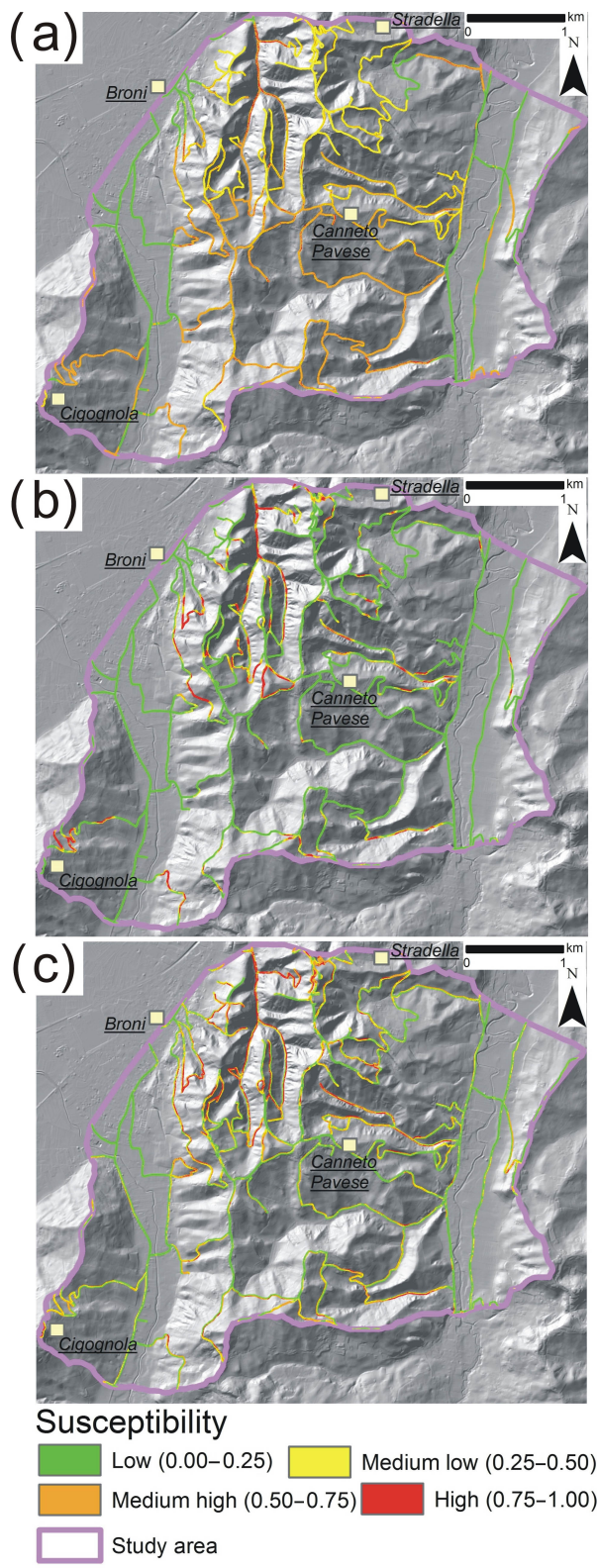

Figure 10. Maps of the susceptibility of the road segments to be affected by shallow landslides: (a) Model 1; (b) Model 2; (c) Model 3.

ceptibility of Model 2 created considering the actual scenario (Fig. 11), the differences on the percentages of the road network classified with low, medium-low, medium-high and high susceptibility by the other reconstructed scenario were negligible, ranging in the order of $0.1-0.2 \%$ (Fig. 13).

\section{Discussions}

In this work, a methodology was developed and tested for classifying, in different susceptibility classes, the traits of a road network potentially hit by sediments of landslides triggered above the road. Different authors (Budetta, 2004;

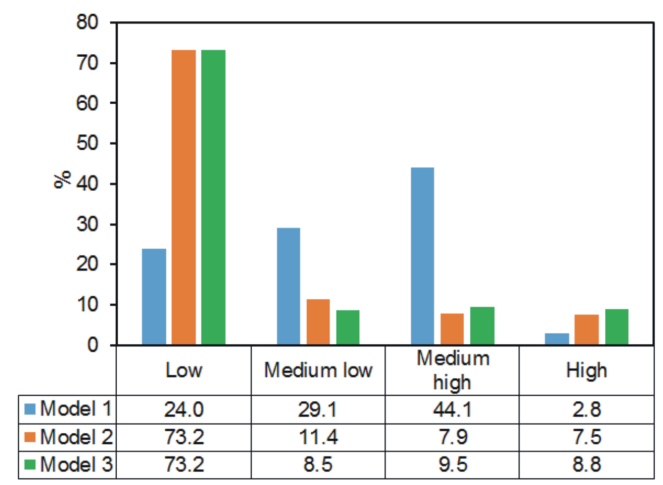

Figure 11. Percentages of the road network classified with low, medium-low, medium-high or high susceptibility to be affected by shallow landslides for each GAM model.

Hearn et al., 2008; Jaiswal et al., 2010a, b, 2011; Quinn et al., 2010; Michoud et al., 2012; Tarolli et al., 2013; Bil et al., 2014, 2017; Penna et al., 2014; Ramesh and Anbazhagan, 2015; Tarolli and Sofia, 2016; Winter et al., 2016; Donnini et al., 2017; Pellicani et al., 2017; Postance et al., 2017; Martinovic et al., 2018) developed similar approaches in other geological or geomorphological settings, based on the implementation of data-driven techniques for the estimation of road susceptibility. For the first time, the proposed methodology allowed to implement a data-driven technique (GAM method) able to take into account the non-linear relationships between the predictors and the response variable (road sector hit by shallow landslides). Moreover, this model also considers a parameter (the index of connectivity) that, if coupled with a landslide inventory, helps assess the potential slope sediments mobilized by the landslide triggering, which can reach the road network in downstream area, also inserting a proxy of landslide runout in the modelling of roads susceptibility.

The models identified some of the input predictors as non-linear variables (in this case, slope curvature, catchment slope, topographic wetness index, distance from shallow landslides source area and index of connectivity), better understanding the complex relationships that are present in an area between predisposing factors and susceptible roads (Phillips, 2006; Goetz et al., 2011). Moreover, before building the model, the procedure developed for the individuation of the most important predictor variables improved the knowledge about mechanisms which regulate the location of the damaged roads in such an area, avoiding collinearity and bias that could reduce the reliability of the susceptibility estimation (Farrar and Glauber, 1967; Hosmer and Lemeshow, 1990; Bai et al., 2010). The robustness of the proposed methodology was also confirmed by the low confidence degree of AUCs measured for the created models (Petschko et al., 2014). The first reconstructed susceptibility model (Model 1) considers the most important predisposing factors in the study area, chosen among those morpholog- 
Table 4. Sensitivity of the different predictor variables to the accuracy of the training sets, the test sets and the final application of the model to the entire study area. The standard deviation of accuracy on the training and test sets was 0.01 for all models, while the range of the $95 \%$ confidence interval of AUC was 0.02 for all the models.

\begin{tabular}{|c|c|c|c|}
\hline GAM model & $\begin{array}{l}\text { Mean accuracy of } \\
\text { training sets }(-)\end{array}$ & $\begin{array}{r}\text { Mean accuracy of } \\
\text { test sets }(-)\end{array}$ & $\begin{array}{r}\text { Mean AUC of } \\
\text { the model (-) }\end{array}$ \\
\hline 1 & 0.71 & 0.70 & 0.74 \\
\hline 2 & 0.90 & 0.90 & 0.94 \\
\hline 3 & 0.82 & 0.82 & 0.83 \\
\hline $2-(\mathrm{CURV}, \mathrm{HEI}, \mathrm{TWI})$ [threshold of selection equal to $90 \%$ ] & 0.84 & 0.84 & 0.88 \\
\hline $2+(\mathrm{CA})[$ threshold of selection equal to $50 \%$ ] & 0.90 & 0.90 & 0.94 \\
\hline $2-(\mathrm{SL})$ & 0.74 & 0.74 & 0.78 \\
\hline $2-(\mathrm{CURV})$ & 0.87 & 0.87 & 0.92 \\
\hline $2-(\mathrm{HEI})$ & 0.85 & 0.77 & 0.91 \\
\hline $2-(\mathrm{CS})$ & 0.79 & 0.79 & 0.83 \\
\hline $2-(\mathrm{TWI})$ & 0.88 & 0.88 & 0.92 \\
\hline $2-(\mathrm{DIST})$ & 0.75 & 0.75 & 0.78 \\
\hline $2-(\mathrm{GEO})$ & 0.84 & 0.85 & 0.88 \\
\hline $2+(\mathrm{ASP})$ & 0.90 & 0.90 & 0.94 \\
\hline $2+(\mathrm{LEN})$ & 0.90 & 0.91 & 0.95 \\
\hline
\end{tabular}

ical, hydrological and geological parameters taken into account for these analyses in different contexts by other authors (Budetta, 2004; Jaiswal et al., 2010a, b, 2011; Quinn et al., 2010; Michoud et al., 2012; Bil et al., 2014, 2017; Penna et al., 2014; Ramesh and Anbazhagan, 2015; Pellicani et al., 2017). The reliability of the model is quite fair, as testified by its AUC value (0.73) and by its high value of FP and TN indexes (22.3 and $45.8 \%$, respectively). According to Model 1, the most susceptible road segments are those located downstream to slopes characterized by high slope gradient $\left(>20^{\circ}\right)$, limited height $(<50 \mathrm{~m})$, high catchment slope $\left(28-30^{\circ}\right)$ and shallow landslides triggering zones located very close to the road network $(40-100 \mathrm{~m})$. These settings are widespread in the entire study area (Bordoni et al., 2015; Persichillo et al., 2017b, 2018), but these particular features are not enough to discriminate more accurately those routes where damages provoked by sediments mobilized by shallow landslides are probable.

Starting from this observation, also IC was inserted in the model for the evaluation of the susceptibility of the roads to be affected by shallow landslides. The other two models were created, differing each other for the type of IC used. Model 2 uses $\mathrm{IC}_{\text {lin }}$ calculated according to the method proposed by Cavalli et al. (2013), where the $W$ factor in the model is evaluated in a linear way. Model 3 uses $\mathrm{IC}_{\mathrm{nl}}$, calculated by means also of a $W$ factor evaluated in a non-linear way and in relation also to the both surface roughness and land use properties of a territory (Fryirs et al., 2007; Cavalli et al., 2008; Cavalli and Marchi, 2008; Gay et al., 2015; Kalantari et al., 2017). In these terms, both $\mathrm{IC}_{\text {lin }}$ and $\mathrm{IC}_{\mathrm{nl}}$ represent a structural connectivity depending on the morphological and land use attributes of a territory (Borselli et al., 2008; Cavalli et al., 2013; Crema and Cavalli, 2015).
The models that consider also sediment connectivity have a higher predictive performance than Model 1 . This is testified by a high AUC values ( 0.94 for Model 2 and 0.83 for Model 3) and by higher values of TP and TN (till 90.0 and $84.8 \%$, respectively). Moreover, FP and FN of both these models are lower than Model 1 (till 10.0 and 15.2 respectively).

A sensitivity analysis to assess the role of each predictor variable on the accuracy of the GAM models was performed. This analysis allowed also evaluating the change in predictive accuracy related to adding or removing a set of predictors according to a threshold of selection different than the used $80 \%$ or related to adding or removing a particular predictor. It is important to highlight that the results of this sensitivity analysis shown referred to the susceptibility model which had the best predictive accuracy, that is Model 2. Instead, the quantitative changes on the predictive accuracy related to different sets of predictors were similar considering both Model 1 and Model 3.

Table 4 showed the results of this sensitivity analysis. According to the percentages of selection of each variable in the 100 -fold bootstrap procedure (Table 2), also thresholds of 50 and $90 \%$ of selection frequency were considered and compared to the used threshold of $80 \%$. A threshold of selection frequency lower than $50 \%$ was not considered significant.

Considering a threshold equal to $50 \%$, also CA (chosen as a linear variable) had to be inserted for modelling the susceptibility. Instead, the mean predictive accuracy of the model, estimated in terms of AUC value, did not change, for both the training set, the test set and the final model. The difference in the predictive accuracy was lower than 0.01. Instead, concerning a threshold equal to $90 \%, \mathrm{CURV}, \mathrm{HEI}$ and TWI had to be removed. In this case, the mean predictive accu- 


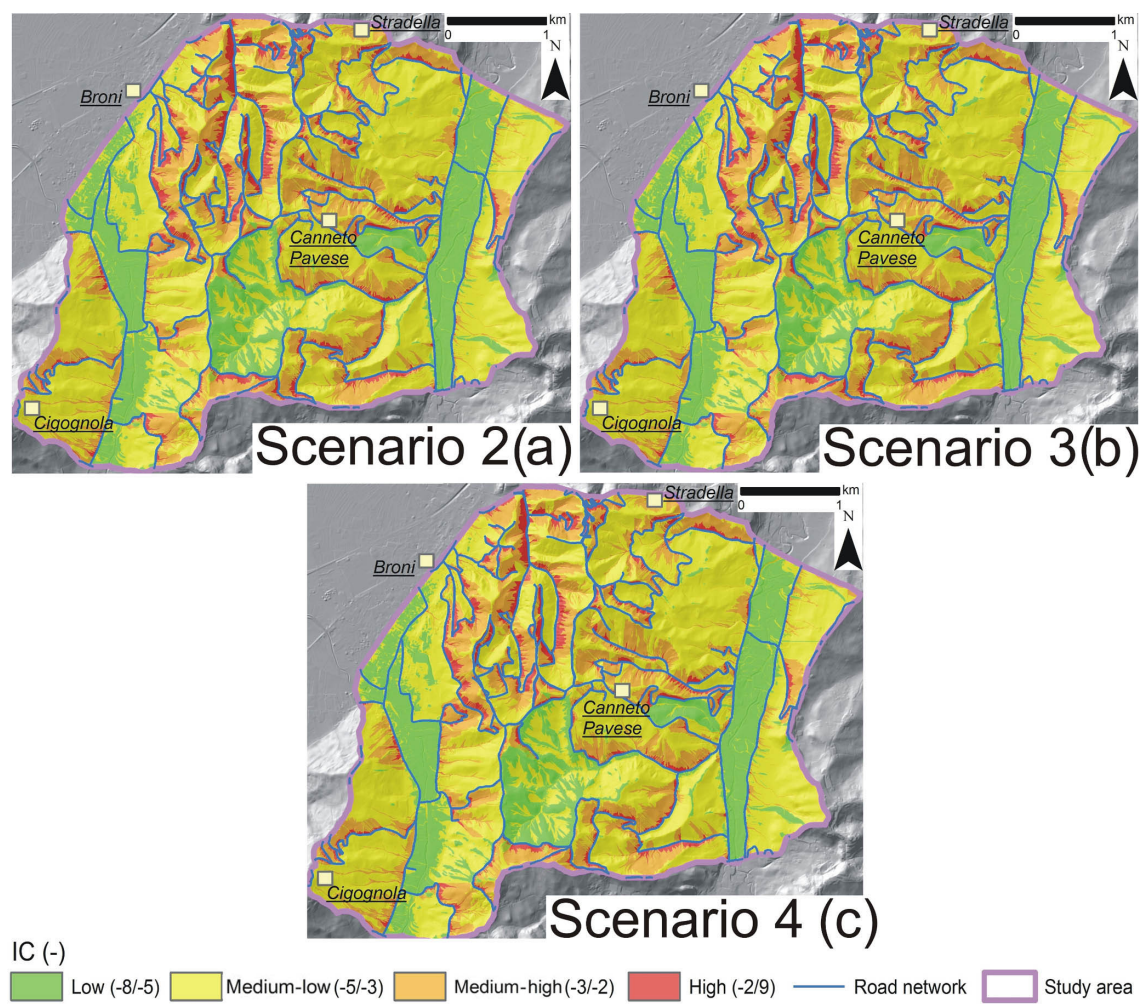

Figure 12. $\mathrm{IC}_{\mathrm{lin}}$ maps of the different land use scenarios considered: (a) Scenario 2: land use distribution equal to that of 1980 (highest extension of vineyards); (b) Scenario 3: transformation of actual uncultivated areas in woodlands; (c) Scenario 4: increase in abandoned areas similar to that which occurred in 1980-2015 period.

racy of the best model (Model 2) decreased from 0.90 to 0.84 and from 0.94 to 0.88 for training/test sets and for the final models, respectively. Removing a predictor or a set of these from the susceptibility model caused a decrease of the accuracy due to a reduction in explaining the physical relations between the predisposing factors and the resulting effects on the response variable, in this case represented by the road sectors hit by shallow landslides. These results demonstrated that a threshold of selection of the predictors equal to $80 \%$ allowed to obtain the sets of predisposing factors able to estimate in the best reliable and effective way the susceptibility of the road network to be affected by shallow landslides.

Furthermore, a sensitivity analysis of the different predictors considered as predisposing factors for road susceptibility was performed. This analysis consisted in running one of the models (e.g., Model 2), created considering a threshold of selection frequency equal to $80 \%$, removing each time one of the selected predictors or adding one of the other predictors each time, whose frequency of selection was lower than $80 \%$. In this way, the sensitivity of the model to each predictor could be quantified.

Removing SL or DIST caused a reduction of the predictive accuracy for both training sets, the test sets and final models of 0.15-0.16. Instead, this reduction was lower than the one quantified if in the model IC was not taken into account
(Model 1). In fact, the absence of IC provoked a decrease in the accuracy of 0.19-0.20. The removal of CS caused a moderate reduction of the accuracy, correspondent to 0.11 . While removing one of the other chosen parameters (CURV, HEI, TWI, GEO) provoked only a slight decrease in the predictive accuracy in the order of 0.02-0.06. This meant that they explained the susceptibility of a road to shallow landslides less than the other selected predictors. Instead, CURV values close to the roads were generally slightly negative (lower than -0.05$)$ and the affected sectors were in correspondence with the lowest CURV values (around -0.40). TWI was generally positive in correspondence with road traits, with values higher than 5 close to sectors affected by shallow landslides. Moreover, damaged road traits were mainly located in areas where GEO was composed of medium-low permeable arenaceous conglomeratic materials (Monte Arzolo sandstones, Rocca Ticozzi conglomerates) or impermeable silty-sandy marly bedrock (Montù Beccaria formation, Sant'Agata Fossili Marls).

Moreover, adding alternatively to the chosen predictors one of the other predisposing factors (CA, ASP, LEN) did not significantly modify the reliability of the models. The predictive accuracy improved 0.01 at most for both training sets, the test sets and final models. ASP close to the roads was very variable, without the identification of peculiar features. 

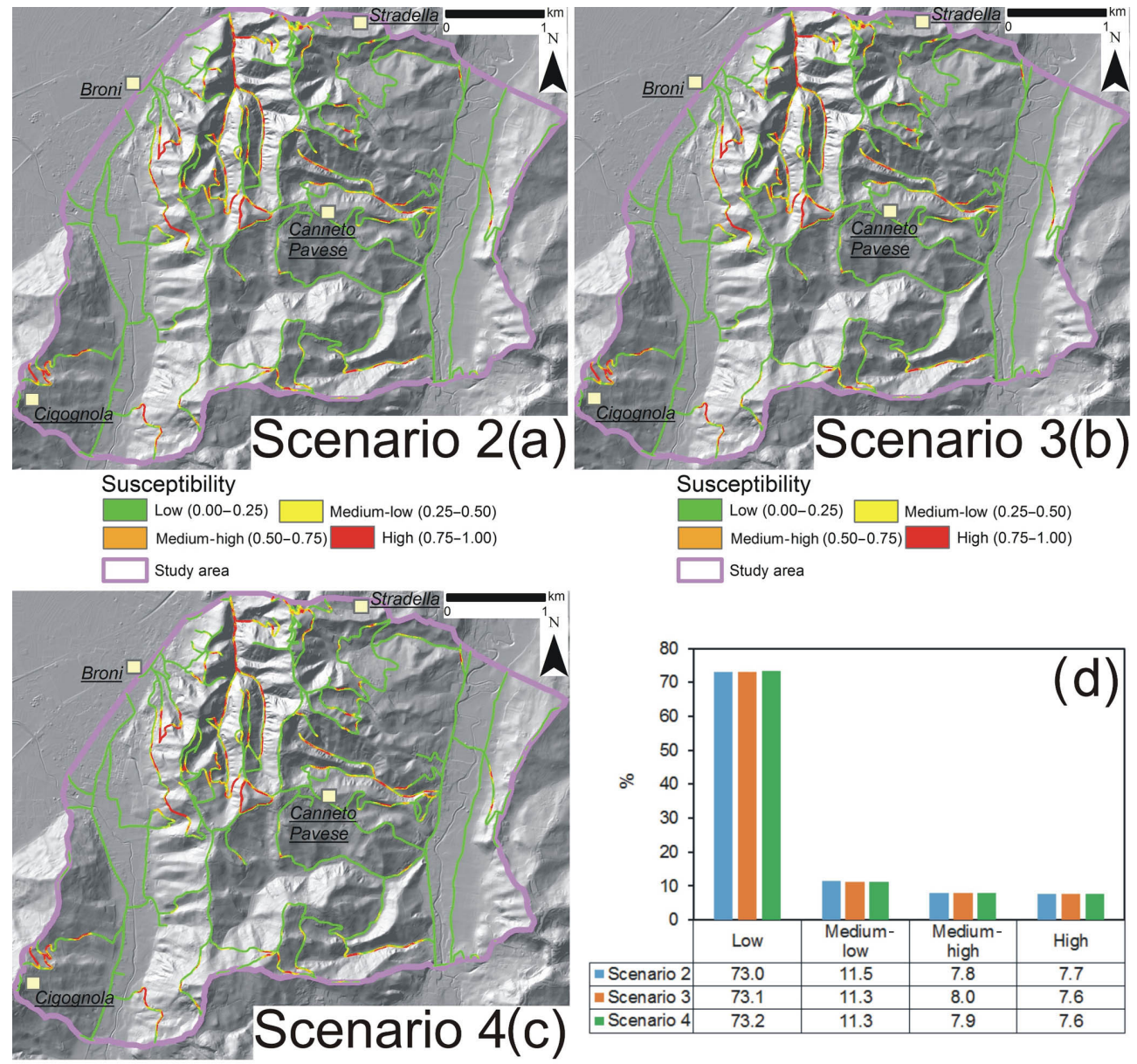

Susceptibility
\begin{tabular}{|l|l}
$\square$ & Low (0.00-0.25) $\square$ Medium-low (0.25-0.50) \\
$\square$ & Medium-high (0.50-0.75) \\
\hline
\end{tabular} High (0.75-1.00)
Study area

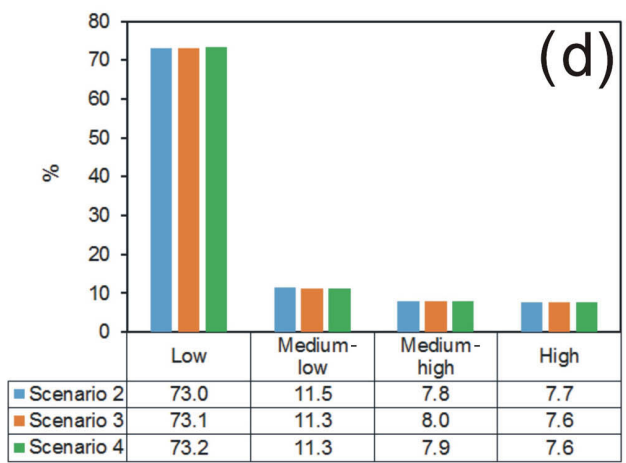

Figure 13. Maps of the susceptibility of the road segments to be affected by shallow landslides according to the different land use scenarios: (a) Scenario 2: land use distribution equal to that of 1980 (highest extension of vineyards); (b) Scenario 3: transformation of actual uncultivated areas in woodlands; (c) Scenario 4: increase in abandoned areas similar to those in the 1980-2015 period; (d) percentage of road network traits of different susceptibility classes for the considered scenarios.

While LEN and CA values close to the road sectors were in a quite narrow range, between 2 and $150 \mathrm{~m}$ and around $102 \mathrm{~m}^{2}$, respectively. The particular distributions of these parameters confirmed their not significant roles in the evaluation of the road susceptibility.

These results confirmed the significant sensitivity of the susceptibility model to IC, especially the one estimated in a linear way. Neglecting IC in these models caused a big decrease in the effectiveness, which significantly affects the susceptibility classification of the road network. Furthermore, SL and DIST also significantly affected the accuracy of the final susceptibility model and had to be considered for obtaining a correct classification of road network. The models were more sensitive to the other chosen predictors (CURV, HEI, TWI, GEO). Instead, the leakage of only one of these parameters could decrease the final reliability of the road susceptibility.

It is important to note that the standard deviation of accuracy on training and test sets was of 0.01 for all the models, while the range of the $95 \%$ confidence interval of AUC was of 0.02 for all the models.

The susceptibility maps produced through Model 2 and Model 3 identify the road sectors characterized by the highest values of IC (IC higher than -3) as the most susceptible. These conditions are measured in several routes regardless of the land cover present in the slope upstream from the road. Among these models, Model 2, that considers IC calculated through a linear manner, performs better than Model 3. Non-linearly reconstructed IC identified less areas with high connectivity than $\mathrm{IC}_{\text {lin }}$. Thus, the estimated probability to be affected by sediment impacts is reduced in these road traits. 


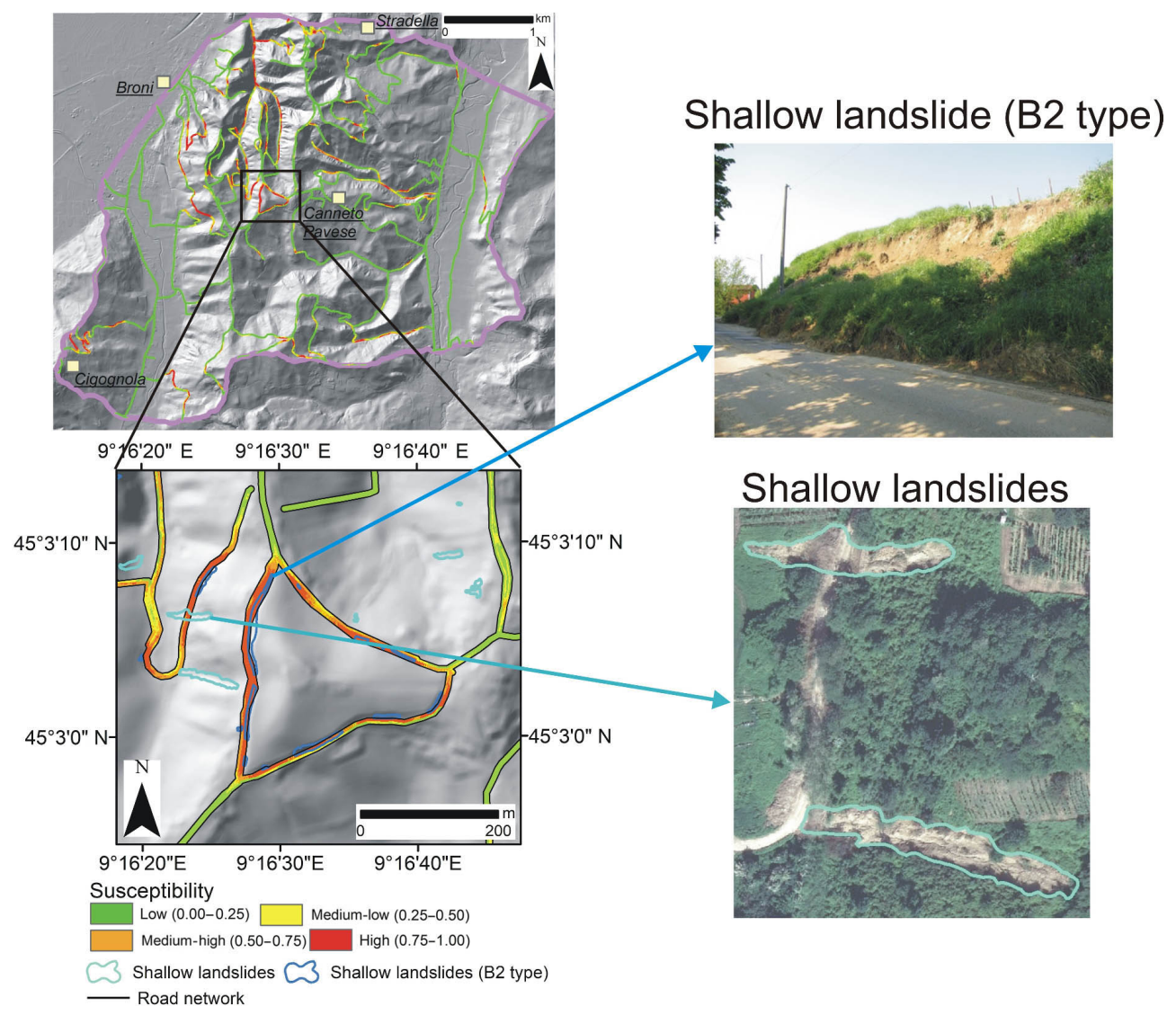

Figure 14. Examples of correct assessment of the susceptibility performed by Model 2, for road sectors hit by B2 type shallow landslides and by other types of phenomena.

$\mathrm{IC}_{\mathrm{nl}}$ is more representative of the sediment connectivity in lowland environments, where the connectivity is also driven by other factors (such as the amount of surface water runoff), together with the morphological features of the hillslopes (Fryirs et al., 2007; Gay et al., 2016; Kalantari et al., 2017). Its application in geomorphological settings characterized by a predominant hilly or mountainous morphology, such as the considered catchment, can implicate an underestimation on the connectivity or disconnectivity of the sediments, influencing the correct assessment of the sectors of an infrastructure threatened by the material mobilized after a triggering event.

The comparison of the best susceptibility model (Model 2) with the distribution of real case of road sectors damaged by sediments mobilized by shallow landslides, that were triggered upstream of the road, has confirmed an excellent predictive performance of this model. It allows the correct identification of both the road sectors hit by the accumulation zones of roto-translational shallow landslides, triggered in the trenches present in halfway roads (B2 type), and the road traits affected by the materials mobilized by shallow landslides, triggered in the slopes upstream of the routes in correspondence with cultivated or abandoned hillslopes (Fig. 14).
This reveals the suppleness of the methodology for estimatnig, in a reliable way, the most susceptible sectors of a road network also in the case of sediment source areas, represented by slope instabilities with different features.

Nevertheless, Model 2 classifies wrongly some road sectors in the study area, as testified by the $15.2 \%$ of FN and of $10 \%$ of FP cases. FN are mostly located in few pixels, sometimes close to other road traits identified with mediumhigh or very-high susceptibility. These situations could be linked to local factors, which may affect road susceptibility that are not completely described by the input predictors chosen for the model. On the contrary, FP cases correspond to road segments where high susceptibility (higher than 0.5) was estimated. These sectors are mostly located near traits already affected by shallow landslide materials in past events (Fig. 15). They are in a buffer of less than $250 \mathrm{~m}$, in particular between 50 and $200 \mathrm{~m}$, respect to sectors hit in past, and they present morphological and connectivity features similar to threatened traits. Hence, they could represent sectors which could be affected by future events that occur in the same study area, whether the settings of this zone and the triggering conditions will stay similar to past events. In these terms, the susceptibility map obtained from Model 2 is useful 


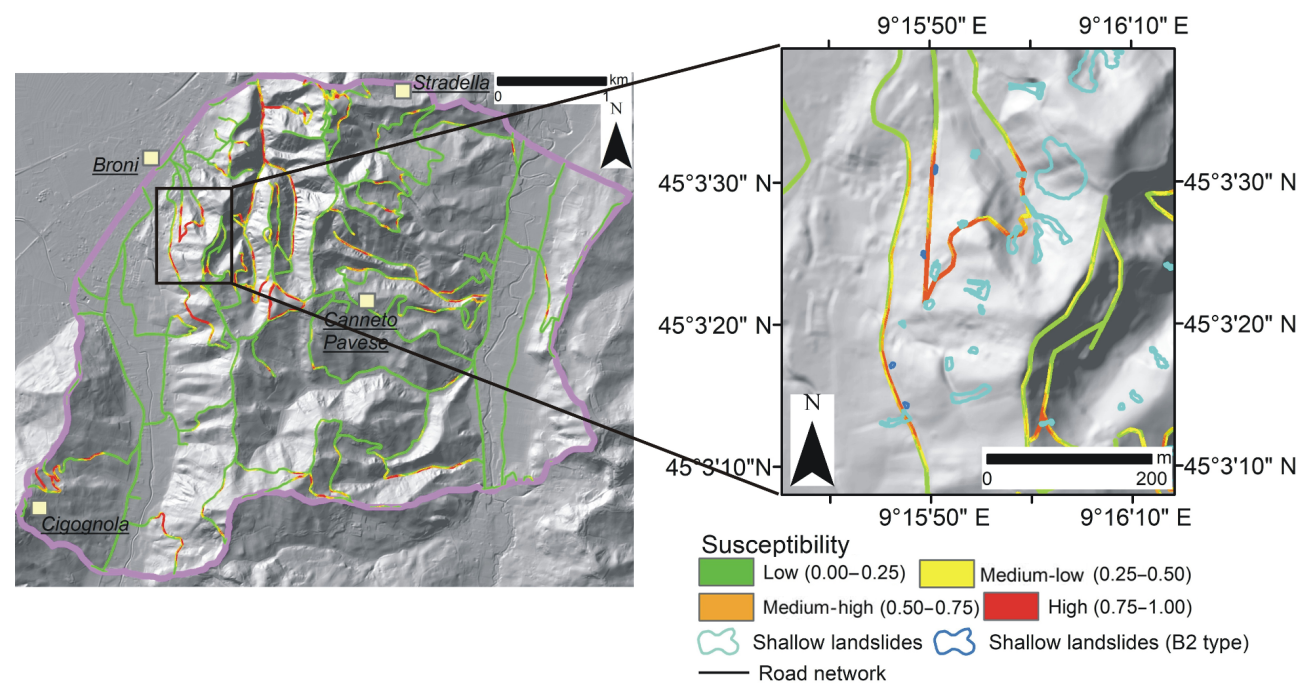

Figure 15. False positive (FP) cases identified through the susceptibility map obtained from Model 2. FP cases are mostly located close (in a range lower than $250 \mathrm{~m}$ ) to road sectors already affected by shallow landslides, in similar morphological and connectivity settings.

for accurately determining the susceptible sectors of a road network, furnishing an important tool for the management of the hazard and for sketching policies of risk reduction out.

Due to the importance of sediment connectivity on the model capability, scenarios of susceptibility were reconstructed, through Model 2, starting from different IC maps that were obtained considering particular land use distributions. In fact, changes in land use cause are represented by changes in the $W$ parameter of the IC calculation, provoking a potential variation in the connectivity distribution. The distribution of susceptibility and of the roads most probably affected by shallow landslides do not change significantly from the actual situation for the three different modelled scenarios (recovery of all cultivated vineyards, break on the abandonment, further increase of the abandoned areas). This is due to the similar values of $W(0.6-0.8)$ characterizing the most widespread land covers of the study area, which thus induce to a limited change in IC value passing from a land use class to another one. Instead, changes in land use distribution could also have effects on the physical morphology of the hillslopes (Fu et al., 2006; Tarolli et al., 2015). For example, the recovery of the cultivation of grapevines in a slope could lead to the development of a drainage system of the superficial and of the shallow waters and to modification on the slope morphology for the implantation of the vineyards. While the abandonment of previously cultivated vineyards induces changes in flow direction and regulation, with direct consequences on sediment production and delivery (Cevasco et al., 2014; Lieskovsky and Kenderessy, 2014; Tarolli et al., 2014; Prosdocimi et al., 2016). These actions could influence the movement of the rainwater and of the sediment mobilized by runoff, then reduce the connectivity and also the potential susceptibility of a road located downstream. Hence, more detailed scenarios of susceptibility changes in relation to land use changes will also take into account the morphological modifications linked to these changes, using a higher resolution DEM (less than $1 \mathrm{~m}$ ).

\section{Conclusions}

In this work, a non-linear data-driven approach, based on GAM, was developed for the evaluation of the susceptible road sectors of a network that could be affected by the sediments delivered from shallow landslides occurred upstream. The methodology also assessed the role of the sediment connectivity on susceptibility estimation, by the implementation of the index connectivity calculated according to a linear or a non-linear approach.

Aside from the use of an inventory of road damages that only referred to three triggering events that occurred between 2009 and 2014, the random partition of the entire dataset in two parts (training and test subsets), within a 100-fold bootstrap procedure, allowed the selection of the most significant predisposing variables. This provided a better description of the occurrence and distribution of the road sectors potentially susceptible to damage induced by shallow landslides.

The best predictive capability was reached by a model, which also took into account the index of connectivity, calculated linearly. This index represented the rates of connectivity and disconnectivity in the studied catchment well, in relation to its morphology (steep slopes and narrow valleys) and land uses (vineyards, abandoned areas and woodlands). Most susceptible road traits resulted in those located below steep slopes with a limited height (lower than $50 \mathrm{~m}$ ), where sediment connectivity is high, regardless of the land use that covered the slope above the road. 
Different scenarios of land use were implemented in order to estimate possible changes in road susceptibility. Land use classes of the study area were characterized by similar effects on connectivity features. The index of connectivity did not change significantly with a consequent leakage of variations also on the susceptibility of the road networks. Larger effects on sediment connectivity could be induced by modifications in the morphology of the slopes (e.g., drainage system, modification of the slope angle) provoked by the abandonment or by the recovery of cultivations. Then this could have effects on the sediment delivery and also on the susceptibility of a road to be hit by sediments mobilized upstream.

The presented methodology allows to identify the most susceptible road sectors that could be hit by sediments delivered by landslides in a robust and reliable way. This tool can represent a fundamental starting point for improving the land management of the slopes where the source areas of the sediments could develop, in order to reduce the damage to the infrastructure and the related risks and economic losses. Moreover, the results of the susceptibility analysis can give asset managers indispensable information on the relative criticality of the different road sectors, thereby allowing attention and economic budgets to be shifted towards the most critical assets, where structural and non-structural mitigation measures could be implemented.

Furthermore, thanks to the flexibility of the model in the selection of the predictors, the proposed model can be applied to areas with different geological, geomorphological and land use features, identifying the most important predisposing factors peculiar of each catchment. This method can be also implemented in areas characterized by much larger catchments than the ones analyzed herein, with the only limit of the availability of high-resolution DEMs and of computational resources. Moreover, the methodology can be applied for estimating the susceptibility and the risks related to landslides affecting other main lifelines, such as railways, gas and oil pipelines, power lines.

Data availability. No public data can be derived from this research. Please contact the corresponding author for any further information.

Author contributions. MB analyzed the data, developed the methodological approach and prepared the manuscript; MGP helped in the development of the methodology and in the interpretation of the results; CM helped in the interpretation of the results and provided guidance and support throughout the research process; SC and $\mathrm{MC}$ helped in building the connectivity scenarios and in supporting their interpretation; CB, YG and MB helped in the development of the data-driven approach and in the interpretation of the results; RG and GD'AA collaborated in writing the manuscript and in the comprehension of the analyses.
Competing interests. The authors declare that they have no conflict of interest.

Special issue statement. This article is part of the special issue "Landslide-road network interactions". It is not associated with a conference.

Acknowledgements. The authors wish to thank the anonymous reviewers for their suggestions and contributions to the work.

Edited by: Faith Taylor

Reviewed by: two anonymous referees

\section{References}

Ayalew, L. and Yamagishi, H.: The application of GIS-based logistic regression for landslide susceptibility mapping in the KakudaYahiko Mountains, Central Japan, Geomorphology, 65, 12-31, https://doi.org/10.1016/j.geomorph.2004.06.010, 2005.

Bai, S. B., Wang, J., Lu, G. N., Zhou, P. G., Hou, S. S., and $\mathrm{Xu}, \mathrm{S}$. N.: Gis-based logistic regression fro landslide susceptibility mapping of the Zhongxian segment in the Three Gorges area, China, Geomorphology, 115, 23-31, https://doi.org/10.1016/j.geomorph.2009.09.025, 2010.

Bathurst, J. C., Burton, A., and Ward, T. J.: Debris flow run-out and landslide sediment delivery model test, J. Hydraul. Eng., 123, 410-419, https://doi.org/10.1061/(ASCE)07339429(1997)123:5(410), 1997.

Begueria, S.: Changes in land cover and shallow landslide activity: a case study in the Spanish Pyrenees, Geomorphology, 74, 196206, https://doi.org/10.1016/j.geomorph.2005.07.018, 2006.

Belsley, D. A., Kuh, E., and Welsch, R. E. (Eds.): Regression diagnostics: identifying influential data and sources of collinearity, John Wiley and Sons, New York, USA, 1980.

Bil, M., Kubecek, J., and Andrasik, R.: An epidemiological approach to determining the risk of road damage due to landslides, Nat. Hazards, 73, 1323-1335, https://doi.org/10.1007/s11069014-1141-4, 2014.

Bil, M., Andrasik, R., Kubecek, J., Krivankova, Z., and Vodak, R.: RUPOK: An online landslide risk tool for road networks, in: Advancing culture of living with landslides, edited by: Mikos, M., Vilimek, V., Yin, Y., and Sassa, K., Springer, Cham, 19-26, 2017.

Bordoni, M., Meisina, C., Valentino, R., Bittelli, M., and Chersich, S.: Site-specific to local-scale shallow landslides triggering zones assessment using TRIGRS, Nat. Hazards Earth Syst. Sci., 15, 1025-1050, https://doi.org/10.5194/nhess-15-1025-2015, 2015.

Borselli, L., Cassi, P., and Torri, D.: Prolegomena to sediment and flow connectivity in the landscape: a GIS and field numerical assessment, Catena, 75, 268-277, https://doi.org/10.1016/j.catena.2008.07.006, 2008.

Brenning, A., Schwinn, M., Ruiz-Páez, A. P., and Muenchow, J.: Landslide susceptibility near highways is increased by 1 order of magnitude in the Andes of southern Ecuador, Loja province, Nat. Hazards Earth Syst. Sci., 15, 45-57, https://doi.org/10.5194/nhess-15-45-2015, 2015. 
Budetta, P.: Assessment of rockfall risk along roads, Nat. Hazards Earth Syst. Sci., 4, 71-81, https://doi.org/10.5194/nhess-4-712004, 2004.

Catani, F., Lagomarsino, D., Segoni, S., and Tofani, V.: Landslide susceptibility estimation by random forests technique: sensitivity and scaling issues, Nat. Hazards Earth Syst. Sci., 13, 2815-2831, https://doi.org/10.5194/nhess-13-2815-2013, 2013.

Cavalli, M. and Marchi, L.: Characterisation of the surface morphology of an alpine alluvial fan using airborne LiDAR, Nat. Hazards Earth Syst. Sci., 8, 323-333, https://doi.org/10.5194/nhess8-323-2008, 2008.

Cavalli, M., Tarolli, P., Marchi, L., and Dalla Fontana, G.: The effectiveness of airborne LiDAR data in the recognition of channel-bed morphology, Catena, 73, 249-260, https://doi.org/10.1016/j.catena.2007.11.001, 2008.

Cavalli, M., Trevisani, S., Comiti, F., and Marchi, L.: Geomorphometric assessment of spatial sediment connectivity in small alpine catchments, Geomorphology, 188, 31-41, https://doi.org/10.1016/j.geomorph.2012.05.007, 2013.

Cevasco, A., Pepe, G., and Brandolini, P.: The influences of geological and land-use settings on shallow landslides triggered by an intense rainfall event in a coastal terraced environment, B. Eng. Geol. Environ., 73, 859-875, https://doi.org/10.1007/s10064013-0544-x, 2014.

Chau, K. T., Sze, Y. L., Fung, M. K., Wong, W. Y., Fong, E. L., and Chan, L. C. P.: Landslide hazard analysis for Hong Kong using landslide inventory and GIS, Comp. Geosci., 30, 429-443, https://doi.org/10.1016/j.cageo.2003.08.013, 2004.

Chen, Z. and Wang, J.: Landslide hazard mapping using logistic regression model in Mackenzie Valley, Canada, Nat. Hazards, 42, 75-89, https://doi.org/10.1007/s11069-006-9061-6, 2007.

Conrad, O., Bechtel, B., Bock, M., Dietrich, H., Fischer, E., Gerlitz, L., Wehberg, J., Wichmann, V., and Böhner, J.: System for Automated Geoscientific Analyses (SAGA) v. 2.1.4, Geosci. Model Dev., 8, 1991-2007, https://doi.org/10.5194/gmd-8-1991-2015, 2015.

Corominas, J., Van Westen, C., Frattini, P., Cascini, L., Malet, J. P., Fotopoulou, S., Catani, F., Van Den Eeckhaut, M., Mavrouli, O., Agliardi, F., Pitilakis, K., Winter, M. G., Pastor, M., Ferlisi, S., Tofani, V., Hervas, J., and Smith, J. T.: Recommendations for the quantitative analysis of landslide risk, B. Eng. Geol. Environ., 73, 209-263, https://doi.org/10.1007/s10064-013-0538-8 2014.

Crema, S. and Cavalli, M.: SedInConnect: A standalone, free and open source tool for the assessment of sediment connectivity, Comp. Geosci., 111, 39-45, https://doi.org/10.1016/j.cageo.2017.10.009, 2018.

Cruden, D. M. and Varnes, D. J.: Landslide types and processes, in: Landslides: investigation and mitigation, edited by: Turner, A. K. and Schuster, R. L., National Academy Press, Washington, D.C., 36-75, 1996.

Dai, F. C. and Lee, C. F.: Landslide characteristics and slope instability modeling using GIS, Lantau Island, Hong Kong, Geomorphology, 42, 213-228, https://doi.org/10.1016/S0169555X(01)00087-3, 2002.

Dai, F. C., Lee, C. F., and Ngai, Y. Y.: Landslide risk assessment and management: an overview, Eng. Geol., 64, 65-87, https://doi.org/10.1016/S0013-7952(01)00093-X, 2002.

D’Amato Avanzi, G., Galanti, Y., Giannecchini, R., and Puccinelli, A.: Fragility of territory and infrastructures resulting from rain- storms in Northern Tuscany (Italy), in: Landslide science and practice, Vol. 6, edited by: Margottini, C., Canuti, P., and Sassa, K., Springer-Verlag Berlin Heidelberg, 239-246, 2013.

Donnini, M., Napolitano, E., Salvati, P., Ardizzone, F., Bucci, F., Fiorucci, F., Santangelo, M., Cardinali, M., and Guzzetti, F.: Impact of event landslides on road networks: a statistical analysis of two Italian case studies, Landslides, 14, 1521-1535, https://doi.org/10.1007/s10346-017-0829-4, 2017.

Fan, L., Lehmann, P., McArdell, B., and Or, D.: Linking rainfallinduced landslides with debris flows runout patterns towards catchment scale hazard assessment, Geomorphology, 280, 1-15, https://doi.org/10.1016/j.geomorph.2016.10.007, 2017.

Fannin, R. and Wise, M.: An empirical-statistical model for debris flow travel distance, Can. Geotech. J., 38, 982-994, https://doi.org/10.1139/t01-030, 2001.

Farrar, D. E. and Glauber, R. R.: Multicollinearity in regression analysis: the problem revisited, Rev. Econ. Stat., 49, 92-107, https://doi.org/10.2307/1937887, 1967.

Fasolini, D: La cartografia dell'uso e copertura del suolo: uno strumento per rilevare il cambiamento del territorio lombardo, RiVista, 1-2, 76-87, 2014.

Fathani, T. F., Legono, D., and Karnawati, D.: A numerical model for the analysis of rapid landslide motion, Geotech. Geol. Eng., 35, 2253-2268, https://doi.org/10.1007/s10706-017-02419, 2017.

Foerster, S., Wilczok, C., Brosinsky, A., and Segl, K.: Assessment of sediment connectivity from vegetation cover and topography using remotely sensed data in a dryland catchment in the Spanish Pyrenees, J. Soils Sediments, 14, 1982-2000, https://doi.org/10.1007/s11368-014-0992-3, 2014.

Fryirs, K. A., Brierley, G. J., Preston, N. J., and Kasai, M.: Buffers, barriers and blankets: the (dis)connectivity of catchment-scale sediment cascades, Catena, 70, 49-67, https://doi.org/10.1016/j.catena.2006.07.007, 2007.

Fu, B. J., Zhang, Q. J., Chen, L. D., Zhao, W. W., Gulinck, H., Liu, G. B., Yang, Q. K., and Zhu, Y. G.: Temporal change in land use and its relationship to slope degree and soil type in a small catchment on the Loess Plateau of China, Catena, 65, 4148, https://doi.org/10.1016/j.catena.2005.07.005, 2006.

Galve, J. P., Cevasco, A., Brandolini, P., and Soldati, M.: Assessment of shallow landslide risk mitigation measures based on land use planning through probabilistic modelling, Landslides, 12, 101-114, https://doi.org/10.1007/s10346-014-0478-9, 2015.

Gariano, S. L. and Guzzetti, F.: Landslides in a changing climate, Earth Sci. Rev., 162, 227-252, https://doi.org/10.1016/j.earscirev.2016.08.011, 2016.

Gay, A., Cerdan, O., Mardhel, V., and Desmet, M.: Application of an index of sediment connectivity in a lowland area, J. Soils Sediments, 16, 280-293, https://doi.org/10.1007/s11368-015-1235y, 2015.

Glade, T.: Landslide occurrence as a response to land use change: a review of evidence from New Zealand, Catena, 51, 297-314, https://doi.org/10.1016/S0341-8162(02)00170-4, 2003.

Goetz, J. N., Guthrie, R. H., and Brenning, A.: Integrating physical and empirical landslide susceptibility models using generalized additive models, Geomorphology, 129, 376-386, https://doi.org/10.1016/j.geomorph.2011.03.001, 2011.

Guzzetti, F., Galli, M., Reichenbach, P., Ardizzone, F., and Cardinali, M.: Landslide hazard assessment in the Collazzone area, 
Umbria, Central Italy, Nat. Hazards Earth Syst. Sci., 6, 115-131, https://doi.org/10.5194/nhess-6-115-2006, 2006.

Hastie, T.: gam: Generalized Additive Models, R package version 1.08, available at: http://CRAN.R-project.org/package=gam, last access: 29 August 2013.

Hastie, T. J. and Tibshirani, R. (Eds.): Generalized additive models, Chapman \& Hall, London, UK, 1990.

Hearn, G., Hunt, T., Aubert, J., and Howell, J.: Landslide impacts on the road network of Lao PDR and the feasibility of implementing a slope management programme, South East Asia Community Access Programme (SEACAP), Department for International Development, UK, 2008.

Hosmer, D. W. and Lemeshow, S.: Applied logistic regression, Wiley, New York, USA, 2000.

Hungr, O.: A model for the runout analysis of rapid flow slides, debris flows, and avalanches, Can. Geotech. J., 32, 610-623, https://doi.org/10.1139/t95-063, 1995.

Jaiswal, P., Van Westen, C. J., and Jetten, V.: Quantitative landslide hazard assessment along a transportation corridor in southern India, Eng. Geol., 116, 236-250, https://doi.org/10.1016/j.enggeo.2010.09.005, 2010a.

Jaiswal, P., van Westen, C. J., and Jetten, V.: Quantitative assessment of direct and indirect landslide risk along transportation lines in southern India, Nat. Hazards Earth Syst. Sci., 10, 1253 1267, https://doi.org/10.5194/nhess-10-1253-2010, 2010b.

Jaiswal, P., Van Westen, C. J., and Jetten, V.: Quantitative assessment of landslide hazard along transportation lines using historical records, Landslides, 8, 279-291, https://doi.org/10.1007/s10346-011-0252-1, 2011.

Jenks, G. F.: The data model concept in statistical mapping, Int. Year. Cart., 7, 186-190, 1967.

Jia, G., Yuan, T., Liu, Y., and Zhang, Y.: A static and dynamic factors-coupled forecasting model or regional rainfall induced landslides: a case study of Shenzhen, Sci. China Ser. E., 51, 164$175,2008$.

Jollifee, I. T. and Stephenson, D. B. (Eds.): Forecast verification: A practitioner's guide in atmospheric science, John Wiley and Sons, New York, USA, 2003.

Kalantari, Z., Cavalli, M., Cantone, C., Crema, S., and Destouni, G.: Flood probability quantification for road infrastructure: Data-driven spatial-statistical approach and case study applications, Sci. Total Environ., 581-582, 386-398, https://doi.org/10.1016/j.scitotenv.2016.12.147, 2017.

Klose, M., Damm, B., and Terhorstet, B.: Landslide cost modeling for transportation infrastructures: a methodological approach, Landslides, 12, 321-334, https://doi.org/10.1007/s10346-0140481-1, 2015.

Klose, M., Auerbach, M., Herrmann, C., Kumerics, C., and Gratzki, A.: Landslide hazards and climate change adaptation of transport infrastructures in Germany, in: Advancing culture of living with landslides, edited by: Mikos, M., Vilimek, V., Yin, Y., and Sassa, K., Springer, Cham, 535-541, 2017.

Kritikos, T. and Davies, T.: Assessment of rainfall-generated shallow landslide/debris-flow susceptibility and runout using a GIS-based approach: application to western Southern Alps of New Zealand, Landslides, 12, 1051-1075, https://doi.org/10.1007/s10346-014-0533-6, 2015.

Lieskovsky, L. and Kenderessy, P.: Modelling the effect of vegetation cover and different tillage practices on soil ero- sion in vineyards: a case study in Vrable (Slovakia) using WATEM/SEDEM, Land Degrad. Dev., 25, 188-196, https://doi.org/10.1002/ldr.2162, 2014.

Lopez-Vicente, M., Poesen, J., Navas, A., and Gaspar, L.: Predicting runoff and sediment connectivity and soil erosion by water for different land use scenarios in the Spanish Pre-Pyrenees, Catena, 102, 62-73, https://doi.org/10.1016/j.catena.2011.01.001, 2013.

Lopez-Vicente, M., Nadal-Romero, E., and Cammeraat, E. L. H.: Hydrological connectivity does change over 70 years of abandonment and afforestation in the Spanish Pyrenees, Land Degrad. Dev., 28, 1298-1310, https://doi.org/10.1002/ldr.2531, 2016.

Maindonald, J. and Braun, W. J. (Eds.): Data analysis and graphics using R: an example based approach, Cambridge Series in Statistical and Probabilistic Mathematics, Cambridge, UK, 2010.

Martinovic, K., Gavin, K., and Reale, C.: Development of a landslide susceptibility assessment for a rail network, Eng. Geol., 215, 1-9, https://doi.org/10.1016/j.enggeo.2016.10.011, 2016.

Martinovic, K., Gavin, K., Reale, C., and Mangan, C.: Rainfall thresholds as a landslide indicator for engineered slopes on the Irish Rail network, Geomorphology, 306, 40-50, https://doi.org/10.1016/j.geomorph.2018.01.006, 2018.

Matulla, C., Hollsi, B., Andre, K., Gringinger, J., Chimani, B., Namyslo, J., Fuchs, T., Auerbach, M., Herrmann, C., Sladek, B., Berghold, H., Gschier, R., and Eichinger-Vill, E.: Climate Change driven evolution of hazards to Europe's transport infrastructure throughout the twenty-first century, Theor. Appl. Climatol., https://doi.org/10.1007/s00704-017-2127-4, 2017.

McLachlan, G. J. (Ed.): Discriminant analysis and statistical pattern recognition, John Wiley \& Sons, New York, USA, 1992.

Michaelides, S.: Vulnerability of transportation to extreme weather and climate change, Nat. Hazards, 72, 1-4, https://doi.org/10.1007/s11069-013-0975-5, 2014.

Michoud, C., Derron, M.-H., Horton, P., Jaboyedoff, M., Baillifard, F.-J., Loye, A., Nicolet, P., Pedrazzini, A., and Queyrel, A.: Rockfall hazard and risk assessments along roads at a regional scale: example in Swiss Alps, Nat. Hazards Earth Syst. Sci., 12, 615-629, https://doi.org/10.5194/nhess-12-615-2012, 2012.

Molinaro, A. M., Simon, R., and Pfeiffer, R. M.: Prediction error estimation: a comparison of resampling methods, Bioinformatics, 21, 3301-3307, https://doi.org/10.1093/bioinformatics/bti499, 2005.

Muenchow, J., Brenning, A., and Richter, M.: Geomorphic process rates of landslides along a humidity gradient in the tropical Andes, Geomorphology, 139, 271-284, https://doi.org/10.1016/j.geomorph.2011.10.029, 2012.

Nemry, F. and Demirel, H.: Impacts of Climate Change on transport: a focus on road and rail transport infrastructures. Publications Office of the European Union, Luxembourg, Luxembourg, 93 pp., 2012.

Olaya, V.: A gentle introduction to SAGA GIS, Edition 1.1 - Rev. 9 December, 216 pp., 2004.

Pastor, M., Blanc, T., Haddad, B., Petrone, S., Sanchez Morles, M., Drempetic, V., Issler, D., Crosta, G. B., Cascini, L., Sorbino, G., and Cuomo, S.: Application of a SPH depth-integrated model to landslide run-out analysis, Landslides, 11, 793-812, https://doi.org/10.1007/s10346-014-0484-y, 2014.

Pellicani, R., Argentiero, I., and Spilotro, G.: GIS-based predictive models for regional-scale landslide susceptibility assessment and risk mapping along road corridors, Geomat. Nat. Haz. Risk, 
8, 1012-1033, https://doi.org/10.1080/19475705.2017.1292411, 2017.

Penna, D., Borga, M., Aronica, G. T., Brigandì, G., and Tarolli, P.: The influence of grid resolution on the prediction of natural and road-related shallow landslides, Hydrol. Earth Syst. Sci., 18, 2127-2139, https://doi.org/10.5194/hess-18-2127-2014, 2014.

Persichillo, M. G., Bordoni, M., and Meisina, C.: The role of land use changes in the distribution of shallow landslides, Sci. Total Environ., 574, 924-937, https://doi.org/10.1016/j.scitotenv.2016.09.125, 2017a.

Persichillo, M. G., Bordoni, M., Meisina, C., Bartelletti, C., Barsanti, M., Giannecchini, R., D’Amato Avanzi, G., Galanti, Y., Cevasco, A., Brandolini, P., and Galve, J. P.: Shallow landslides susceptibility assessment in different environments, Geomat. Nat. Haz. Risk, 8, 748-771, https://doi.org/10.1080/19475705.2016.1265011, 2017b.

Persichillo, M. G., Bordoni, M., Cavalli, M., Crema, S., and Meisina, C.: The role of human activities on sediment connectivity of shallow landslides, Catena, 160, 261-274, https://doi.org/10.1016/j.catena.2017.09.025, 2018.

Petschko, H., Brenning, A., Bell, R., Goetz, J., and Glade, T.: Assessing the quality of landslide susceptibility maps - case study Lower Austria, Nat. Hazards Earth Syst. Sci., 14, 95-118, https://doi.org/10.5194/nhess-14-95-2014, 2014.

Phillips, J. D.: Sources of nonlinearity and complexity in geomorphic systems, Prog. Phys. Geogr., 27, 1-23, https://doi.org/10.1191/0309133303pp340ra, 2003.

Phillips, J. D.: Evolutionary geomorphology: thresholds and nonlinearity in landform response to environmental change, Hydrol. Earth Syst. Sci., 10, 731-742, https://doi.org/10.5194/hess-10731-2006, 2006.

Postance, B., Hillier, J., Dijkstra, T., and Dixon, N.: Extending natural hazard impacts: an assessment of landslide disruptions on a national road transportation network, Environ. Res. Lett., 12, 14010, https://doi.org/10.1088/1748-9326/aa5555, 2017.

Prosdocimi, M., Cerdà, A., and Tarolli, P.: Soil water erosion on Mediterranean vineyards: A review, Catena, 141, 1-21, https://doi.org/10.1016/j.catena.2016.02.010, 2016.

Quinn, P., Beven, K., Chevallier, P., and Planchon, O.: The prediction of hillslope flow paths for distributed hydrological modelling using digital terrain models, Hydrol. Process., 5, 59-79, https://doi.org/10.1002/hyp.3360050106, 1991.

Quinn, P. E., Hutchinson, D. J., Diederichs, M. S., and Rowe, R. K.: Regional-scale landslide susceptibility mapping using the weights of evidence method: an example applied to linear infrastructure, Can. Geotech. J., 47, 905-927, https://doi.org/10.1139/T09-144, 2010.

Ramesh, V. and Anbazhagan, S.: Landslide susceptibility mapping along Kolli hills Ghat road section (India) using frequency ratio, relative effect and fuzzy logic models, Environ. Earth Sci., 73, 8009-8021, https://doi.org/10.1007/s12665-014-3954-6, 2015.

Reichenbach, P., Busca, C., Mondini, A. C., and Rossi, M.: The influence of land use change on landslide susceptibility zonation: the Briga catchment test site (Messina, Italy), Environ. Manage., 54, 1372-1384, https://doi.org/10.1007/s00267-014-0357$0,2014$.

Rural Police Regulation: Regolamento di Polizia Rurale, Comune di Canneto Pavese, Italy, 17 pp., 2008.
Salvati, P., Bianchi, C., Fiorucci, F., Giostrella, P., Marchesini, I., and Guzzetti, F.: Perception of flood and landslide risk in Italy: a preliminary analysis, Nat. Hazards Earth Syst. Sci., 14, 2589 2603, https://doi.org/10.5194/nhess-14-2589-2014, 2014.

Seibert, J. and McGlynn, B. L.: A new triangular multiple flow direction algorithm for computing upslope areas from gridded digital elevation models, Water Resour. Res., 43, W04501, https://doi.org/10.1029/2006WR005128, 2007.

Seibert, J., Stendahl, J., and Sorensen, R.: Topographical influences on soil properties in boreal forests, Geoderma, 141, 139-148, https://doi.org/10.1016/j.geoderma.2007.05.013, 2007.

Sidle, R. C. and Ochiai, H.: Landslides: Processes, prediction, and land use, Water Resources Monograph, AGU, Washington D.C., 2006.

Sidle, R. C., Ghestem, M., and Stokes, A.: Epic landslide erosion from mountain roads in Yunnan, China - challenges for sustainable development, Nat. Hazards Earth Syst. Sci., 14, 3093-3104, https://doi.org/10.5194/nhess-14-3093-2014, 2014.

Spitalnic, S.: Test properties 2: likelihood ratios, Bayes' formula, and receiver operating characteristic curves, Hosp. Physician, 40, 53-58, 2004.

Strauch, R. L., Raymond, C. L., Rochefort, R. M., Hamlet, A. F., and Lauver, C.: Adapting transportation to climate change on federal lands in Washington State, U.S.A, Climatic Change, 130, 185-199, https://doi.org/10.1007/s10584-015-1357-7, 2015.

Surian, N., Righini, M., Lucia, A., Nardi, L., Amponsah, W., Benvenuti, M., Borga, M., Cavalli, M., Comiti, F., Marchi, L., Rinaldi, M., and Viero, A.: Channel response to extreme floods: Insights on controlling factors from six mountain rivers in northern Apennines, Italy, Geomorphology, 272, 78-91, https://doi.org/10.1016/j.geomorph.2016.02.002, 2016.

Tarolli, P. and Sofia, G.: Human topographic signatures and derived geomorphic processes across landscapes, Geomorphology, 255, 140-161, https://doi.org/10.1016/j.geomorph.2015.12.007, 2016.

Tarolli, P., Calligaro, S., Cazorzi, F., and Dalla Fontana, G.: Recognition of surface flow processes influenced by roads and trails in mountain areas using high-resolution topography, Eur. J. Remote Sens., 46, 176-197, https://doi.org/10.5721/EuJRS20134610, 2013.

Tarolli, P., Preti, F., and Romano, N.: Terraced landscapes: from an old best practice to a potential hazard for soil degradation due to land abandonment, Anthropocene, 6, 10-25, https://doi.org/10.1016/j.ancene.2014.03.002, 2014.

Tarolli, P., Sofia, G., Calligaro, S., Prosdocimi, M., Preti, F., and Dalla Fontana, G.: Vineyards in terraced landscapes: New opportunities from LIDAR data, Land Degrad. Dev., 26, 92-102, https://doi.org/10.1002/ldr.2311, 2015.

Tiranti, D., Cavalli, M., Crema, S., Zerbato, M., Graziadei, M., Barbero, S., Cremonini, R., Silvestro, C., Bodrato, G., and Tresso, F.: Semi-quantitative method for the assessment of debris supply from slopes to river in ungauged catchments, Sci. Total Environ., 554-555, 337-348, https://doi.org/10.1016/j.scitotenv.2016.02.150, 2016.

Van Westen, C. J., Asch T. W. J., and Soeters, R.: Landslide hazard and risk zonation - why is it still so difficult?, B. Eng. Geol. Environ., 65, 67-184, https://doi.org/10.1007/s10064-005-00230, 2006. 
Van Westen, C. J., Castellanos, E., and Kuriakose, S. L.: Spatial data for landslide susceptibility, hazard, and vulnerability assessment: an overview, Eng. Geol., 102, 112-131, https://doi.org/10.1016/j.enggeo.2008.03.010, 2008.

Varnes, D. J. (Ed.): Landslide hazard zonation - a review of principles and practice, UNESCO, Paris, France, 1984.

Vercesi, P. and Scagni, G.: Osservazioni sui depositi conglomeratici dello sperone collinare di Stradella, Rendiconti della Società Geologica Italiana, 7, 23-26, 1984.

Winchell, M. F., Jackson, S. H., Wadley, A. M., and Srinivasan, R.: Extension and validation of a geographic information systembased method for calculating the revised universal soil loss equation length-slop factor for erosion risk assessments in large watersheds, J. Soil Water Conserv., 63, 105-111, 2008.

Winter, M. G., Shearer, B., Palmer, D., Peeling, D., Harmer, C., and Sharpe J.: The economic impact of landslides and floods on the road network, Procedia Eng., 143, 1425-1434, https://doi.org/10.1016/j.proeng.2016.06.168, 2016.

Zaffaroni, P.: Confronto fra CLC 2006 e DUSAF 2.1 della Regione Lombardia, 9-12 November 2010, ASITA, Brescia, 2010.
Wischmeier, W. H. and Smith, D. D.: Predicting rainfall erosion losses: a guide to conservation planning with Universal Soil Loss Equation (USLE), in: Agriculture Handbook, No. 703, Department of Agriculture, Washington, D. C., 1978.

Zezere, J. L., Oliveira, S. C., Garcia, R. A. C., and Reis, E.: Landslide risk analysis in the area North of Lisbon (Portugal): evaluation of direct and indirect costs resulting from a motorway disruption by slope movements, Landslides, 4, 123-136, https://doi.org/10.1007/s10346-006-0070-z, 2007.

Zevenbergen, L. W. and Thorne, C. R.: Quantitative analysis of land surface topography, Earth Surf. Proc. Land., 12, 47-56, https://doi.org/10.1002/esp.3290120107, 1987.

Zizioli, D., Meisina, C., Valentino, R., and Montrasio, L.: Comparison between different approaches to modeling shallow landslide susceptibility: a case history in Oltrepo Pavese, Northern Italy, Nat. Hazards Earth Syst. Sci., 13, 559-573, https://doi.org/10.5194/nhess-13-559-2013, 2013. 